\title{
əPyrocumulonimbus Firepower Threshold: Assessing the Atmospheric Potential for pyroCb
}

\author{
K. J. TORY ${ }^{\mathrm{a}, \mathrm{b}}$ AND J. D. KEPERT ${ }^{\mathrm{a}, \mathrm{b}}$ \\ ${ }^{\mathrm{a}}$ Bureau of Meteorology, Melbourne, Victoria, Australia \\ ${ }^{\mathrm{b}}$ Bushfire and Natural Hazards Cooperative Research Centre, Melbourne, Victoria, Australia
}

(Manuscript received 13 February 2020, in final form 5 October 2020)

\begin{abstract}
Pyrocumulonimbus (pyroCb) clouds are difficult to predict and can produce extreme and unexpected wildfire behavior that can be very hazardous to fire crews. Many forecasters modify conventional thunderstorm diagnostics to predict pyroCb potential, by adding temperature $(\Delta \theta)$ and moisture increments $(\Delta q)$ to represent smoke plume thermodynamics near the expected plume condensation level. However, estimating these $\Delta \theta$ and $\Delta q$ increments is a highly subjective process that requires expert knowledge of all factors that might influence future fire size and intensity. In this paper, instead of trying to anticipate these $\Delta \theta$ and $\Delta q$ increments for a particular fire, the minimum firepower required to generate pyroCb for a given atmospheric environment is considered. This concept, termed the pyroCb firepower threshold (PFT) requires only atmospheric information, removing the need for subjective estimates of the fire contribution. A simple approach to calculating PFT is presented that incorporates only basic plume-rise physics, yielding an analytic solution that offers important insight into plume behavior and pyroCb formation. Minimum increments of $\Delta \theta$ and $\Delta q$ required for deep, moist convection, plus a minimum cloud-base height $\left(z_{\mathrm{fc}}\right)$, are diagnosed on a thermodynamic diagram. Briggs's plume rise equations are used to convert $\Delta \theta, z_{\mathrm{fc}}$, and a mean horizontal wind speed $U$ to a measure of the PFT: the minimum heat flux entering the base of the plume. This PFT is proportional to the product of $U, \Delta \theta$, and the square of $z_{\mathrm{fc}}$. Plume behavior insights provided by the Briggs's equations are discussed, and a selection of PFT examples presented.
\end{abstract}

KEYWORDS: Cumulus clouds; Thunderstorms; Forest fires

\section{Introduction}

In favorable atmospheric conditions, large hot fires can produce pyrocumulonimbus (pyroCb) clouds in the form of deep convective columns resembling conventional thunderstorms, which may be accompanied by strong and erratic inflow, potentially dangerous downbursts, and lightning strikes. These in turn can enhance fire spread rates and intensity, cause sudden changes in fire spread direction (e.g., Fromm et al. 2006; Trentmann et al. 2006; Rosenfeld et al. 2007; Fromm et al. 2012), and ignite additional fires (e.g., Dowdy et al. 2017). Dangerous pyroCb conditions are not very well understood and are difficult to forecast.

Conventional thunderstorm diagnostics such as convective available potential energy (CAPE; a measure of the atmospheric thermodynamic instability) have been used to gauge the potential for deep, moist pyro-convection (e.g., Potter 2005). CAPE is a measure of the buoyancy potential of a hypothetical air parcel once it has been lifted adiabatically until it condenses and then moist adiabatically until it is buoyant relative to the surrounding environment. Given that fires provide additional heat and moisture to air parcels rising in a smoke plume, potential temperature $\theta$ and specific humidity $q$ perturbations can be added to a suitable air parcel to represent a hypothetical smoke-plume parcel at the parcel's condensation level (e.g., fireCAPE, Potter 2005). This approach can be

\footnotetext{
Denotes content that is immediately available upon publication as open access.

Corresponding author: Dr. Kevin J. Tory, kevin.tory@bom. gov.au
}

useful for identifying environments that are potentially unstable to tall vigorous smoke plumes, but otherwise too stable for conventional deep, moist convection.

Examples of fireCAPE are illustrated in Fig. 1a, for a 1000 local summer time (LST) sounding at Wagga Wagga (New South Wales, Australia) on 18 January 2003, the morning of the infamous Canberra fire that produced multiple pyroCb (Fromm et al. 2006; McRae et al. 2012). ${ }^{1}$ Here mixed-layer (ML) values of $\theta$ and $q$ have been used to define the lifting condensation level (LCL) to ensure air entrained into the plume from all levels is represented as the plume rises to the LCL (Tory et al. 2018, section 5c). Two fireCAPE examples are included, using potential temperature and specific humidity perturbations of $2 \mathrm{~K}$ and $2 \mathrm{~g} \mathrm{~kg}^{-1}$ (green lines) following Potter (2005), and $2 \mathrm{~K}$ and $0.2 \mathrm{~g} \mathrm{~kg}^{-1}$ (pale blue lines) consistent with heat to moisture ratios of Luderer et al. (2009). The moist adiabat emanating from the ML-LCL (purple dotted line) is everywhere colder than the environment (i.e., zero CAPE) illustrating that the atmosphere is stable to moist convection, as might be expected for this time in the morning. The increments of $2 \mathrm{~K}$ and $2 \mathrm{~g} \mathrm{~kg}^{-1}$ result in very minimal fireCAPE (Fig. 1, shaded), and the increments of $2 \mathrm{~K}$ and $0.2 \mathrm{~g} \mathrm{~kg}^{-1}$ produce zero fireCAPE.

These increments were included primarily to illustrate the sensitivity of increment choices using values suggested in the literature, but it also draws attention to a discussion on realistic ratios of temperature to moisture increments. Luderer et al. (2009) argued that Potter's hypothetical 1:1 ratio (Fig. 1, green lines)

\footnotetext{
${ }^{1}$ This sounding is distant from the fire in space and time, and thus not necessarily a good representation of the actual environment the pyroCb developed in. However, forecasters using fireCAPE or the PFT are often faced with this additional uncertainty.
} 

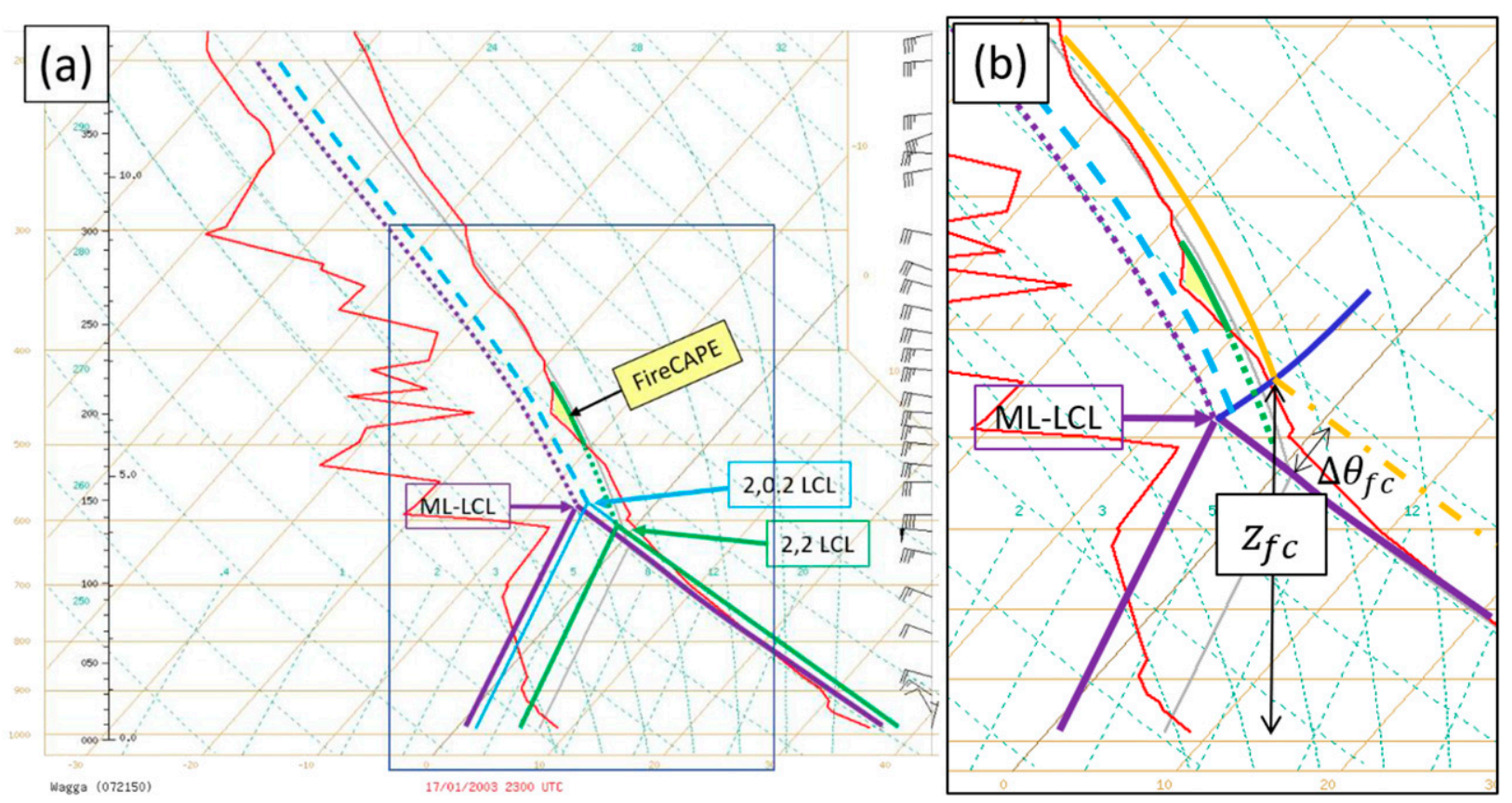

FIG. 1. (a) Thermodynamic diagram from Wagga Wagga, 2300 UTC17 Jan 2003 (1000 LST 18 Jan), on the morning of the Canberra fires that spawned a very substantial pyroCb later that day. The red lines are the environment temperature and dewpoint temperature. The purple lines represent mixed-layer average potential temperature and specific humidity, with the mixed-layer lifting condensation level (ML-LCL) at their apex, and a moist adiabat (purple dotted line) indicating a ML lifted saturated parcel path. The green lines represent a hypothetical fireCAPE calculation (Potter 2005; using perturbations of $2 \mathrm{~K}$ and $2 \mathrm{~g} \mathrm{~kg}^{-1}$ ) and the pale blue lines represent a more realistic fireCAPE (Luderer et al. 2009; using perturbations of $2 \mathrm{~K}$ and $0.2 \mathrm{~g} \mathrm{~kg}^{-1}$ ). (b) Zoomed rectangular inset of (a) with additional quantities from Tory et al. (2018). The SP curve (dark blue) emanates from the ML-LCL. The minimum equivalent potential temperature $\theta_{e, \text { min }}$ plume path that is warmer than the environment (positively buoyant) everywhere between the SP curve and a designated level above, describes the free-convection moist adiabat (orange curve). The height of the intersection of these two curves, $z_{\mathrm{fc}}$, defines the minimum height the plume must rise, and $\Delta \theta_{\mathrm{fc}}$ defines how much warmer than $\theta_{\mathrm{ML}}$ the plume needs to be for free convection to develop.

was unrealistically moist, which overestimated fireCAPE and produced a plume LCL lower than the environment LCL (cf. the ML-LCL with 2,2 LCL in Fig. 1). In comparison, the more realistic (but still relatively moist, according to Luderer et al., 2009) 10:1 ratio (Fig. 1, cyan lines), shows a plume LCL slightly more elevated than the ML-LCL, and a moist plume parcel path (cyan dashed line) about $5^{\circ} \mathrm{C}$ cooler than the 1:1 ratio equivalent (green dotted line).

While fireCAPE for both sets of perturbations show reduced stability, there is insufficient instability to support deep moist convection. Adding larger increments will, of course, increase fireCAPE and the diagnosed potential for deeper moist convection but the increment magnitude is highly subjective. Australian fire-weather forecasters tend to adjust the increments according to expected fire size and intensity (based on fire-weather conditions, fuels, terrain, and expected wind changes), and they may vary the ratio of temperature to moisture increments with fuel type (K. Parkyn, D. Grant, and Z. Berry-Porter 2019, personal communication). However, without in situ observations of the plume thermodynamics it is very difficult to know what increments are appropriate for any given plume. Furthermore, given the strong dependence of plume rise on background wind speed (e.g., Briggs 1975; Weil 1988) the increment choices should also consider wind speed.

In this paper an alternative approach is proposed. Instead of trying to anticipate how much additional heat and moisture a fire might be capable of delivering to an expected condensation level, we invert the problem and consider what is the minimum firepower ${ }^{2}$ (i.e., the total heat flux entering the base of the plume) required to generate deep, moist convection (pyroCb) in any given atmospheric environment. Thus, the concept of a pyroCb firepower threshold (PFT) is introduced to diagnose the favorability of any given atmospheric environment for pyroCb formation. Importantly, this approach does not require any fire information, and it considers the impact of both the kinematic and thermodynamics of the atmospheric environment on potential plume rise. We take a simple approach that yields an analytic PFT solution that is easy to understand and offers very useful insight into potential plume behavior. We anticipate that additional complexity will be built into future PFT diagnostics when accurate firepower observations become more readily available for verification. It is important that the diagnostic remains as transparent to users as possible, because diagnostics based on clear physical principles facilitate user interpretation and confidence.

\footnotetext{
${ }^{2}$ Firepower is often reported as a heat flux per unit area $\left(\mathrm{W} \mathrm{m}^{-2}\right)$, whereas in this paper firepower refers to the entire, or area-integrated, heat flux (W).
} 
The simple PFT presented in this paper draws on the plume saturation point (SP) concept of Tory et al. (2018). The plume SP on a thermodynamic diagram depends on the heat and moisture produced by the fire and how diluted the plume has become from air entrained from the surrounding environment. Assuming the fire releases heat and moisture in a specific ratio, these SPs line up on a SP curve (e.g., Fig. 1b dark blue curve). From this SP curve hypothetical moist-plume paths emanate (lines of constant equivalent potential temperature $\theta_{e}$ ), representing the set of possible moist plume parcel traces. The path with minimum $\theta_{e}\left(\theta_{e, \min }\right)$ that is warmer than the environment everywhere between the SP curve and a designated cloud-top height represents the moist-plume parcel pathway that has enough buoyancy to freely convect to that designated level (Fig. 1b, yellow curve). It represents the minimum-energy pyroCb parcel path.

This procedure not only identifies the temperature and moisture increments required, but the height the plume must rise for the instability to be released, the free-convection height $z_{\mathrm{fc}}$ (Fig. 1b). The temperature increment, expressed as a potential temperature increment $\Delta \theta_{\mathrm{fc}}$, is a measure of how much warmer the plume needs to be, at $z_{\mathrm{fc}}$, than the mixed-layer environment, to ensure it has sufficient buoyancy to penetrate any inversions above that might inhibit the deep, moist-plume ascent. These quantities are fundamental to determining the favorability of the atmosphere to support pyroCb development, since the higher the plume must rise to condense and the greater the buoyancy it requires to penetrate inversions, the greater the required heat flux entering the plume.

To quantify the minimum heat flux entering the plume (the PFT), a relationship between the plume buoyancy at $z_{\mathrm{fc}}$ and the heat flux or buoyancy flux at the surface, is required, which can be obtained from a bulk plume model. In the next section, bulk plume models are introduced and their relevance to the wildfire plume discussed. In section 3 the simplest suitable bulk plume model, the set of Briggs's equations, is described, and equations that provide insight into plume behavior are derived, and the insight discussed. The simple PFT is introduced in section 4, where further insight from the PFT equation is discussed, and an approximate method for calculating PFT manually from an atmospheric sounding is explained. Manual PFT calculations for a selection of events are presented in section 5, to provide a sense of how this PFT varies throughout the day and from event to event. The paper is summarized in section 6.

\section{Can bulk plume models be used for the PFT?}

Bulk plume models are derived from the full three-dimensional Navier-Stokes equations by averaging over a plume volume (e.g., Briggs 1975; Weil 1988). The bulk plume equations express the conservation of mass, momentum, and thermodynamic energy as mass, momentum, and buoyancy fluxes that vary with distance along the plume axis. The Boussinesq approximation ensures a constant relationship between mass and volume, and allows the mass/volume flux to be represented as a function of the plume velocity integrated over a plume cross section, i.e., the average or "bulk" plume velocity. Similarly, the buoyancy flux is expressed as the integrated buoyancy transported by the bulk along-plume flow. This treatment of the along-plume fluxes as bulk properties allows plume entrainment to be treated in bulk too, so that the variation in mass/volume and buoyancy with along-plume distance is expressed as a bulk inward entrainment flux.

Realistic solutions require a physically realistic closure assumption. The entrainment function provides this closure. It is assumed that entrainment is governed by the turbulence at the plume edge, and that it scales with the difference in velocity between the plume and environment-a tried and true relationship identified in numerous boundary layer and turbulence studies, and consistent with the turbulent kinetic energy equation (e.g., Stull 1988). Entrainment constants have been identified through experimentation and observation, and found to be very consistent across a range of scales and fluids (e.g., Briggs 1984). In consideration of the question posed in the section title, bulk plume models are underpinned by the physics of fluid dynamics. (They are not a set of empirical relationships determined by fitting equations to experimental or observational data.) The approximations used to generate solutions are based on well-established and well-understood fluid dynamical relationships. While the solutions describe time- and spaceaveraged plume structure and properties (they do not describe turbulent motion within the plume), these mean properties are ideal for the PFT, which needs to capture plume behavior that persists long enough to generate a thunderstorm, (perhaps several tens of minutes).

The simplest bulk plume model that can be used for the PFT, i.e., diagnose the buoyancy distribution with height, is the set of Briggs's equations, which represent an analytic solution of the bulk plume equations for a plume in a constant horizontal wind $U$ and neutrally stable environment (Briggs 1975, 1984). These conditions are fairly typical of elevated fire danger conditions, which generally occur in a deep well-mixed boundary layer (e.g., Peterson et al. 2017). Briggs's plume geometry is described by an equation for the plume centerline height $z_{c}$ with distance downwind $x$ :

$$
z_{c}=\left[\left(\frac{3}{2 \beta^{2}}\right) \frac{B_{\mathrm{flux}}}{\pi U^{3}}\right]^{1 / 3} x^{2 / 3},
$$

and an equation for the radius $R$ of the circular plume crosssectional area centered on $z_{c}$ :

$$
R=\beta z_{c} .
$$

Here $\beta$ is the constant entrainment parameter, $B_{\text {flux }}$ is the buoyancy flux (conserved in the plume), $\pi$ is the circle constant, and $R$ represents the radius of Briggs's "dynamic" plume. To explain the dynamic plume, we refer to the schematic in Fig. 2, which depicts the outlines of two plumes, one inside the other. The "internal" plume (shaded) contains the plume gases, whereas the dynamic plume (pale blue lines) includes the internal plume plus a hypothetical layer of surrounding environmental air lifted by the rising internal plume. Prime symbols $\left({ }^{\prime}\right)$ are used when referencing the internal plume radius and associated entrainment parameter:

$$
R^{\prime}=\beta^{\prime} z_{c}
$$




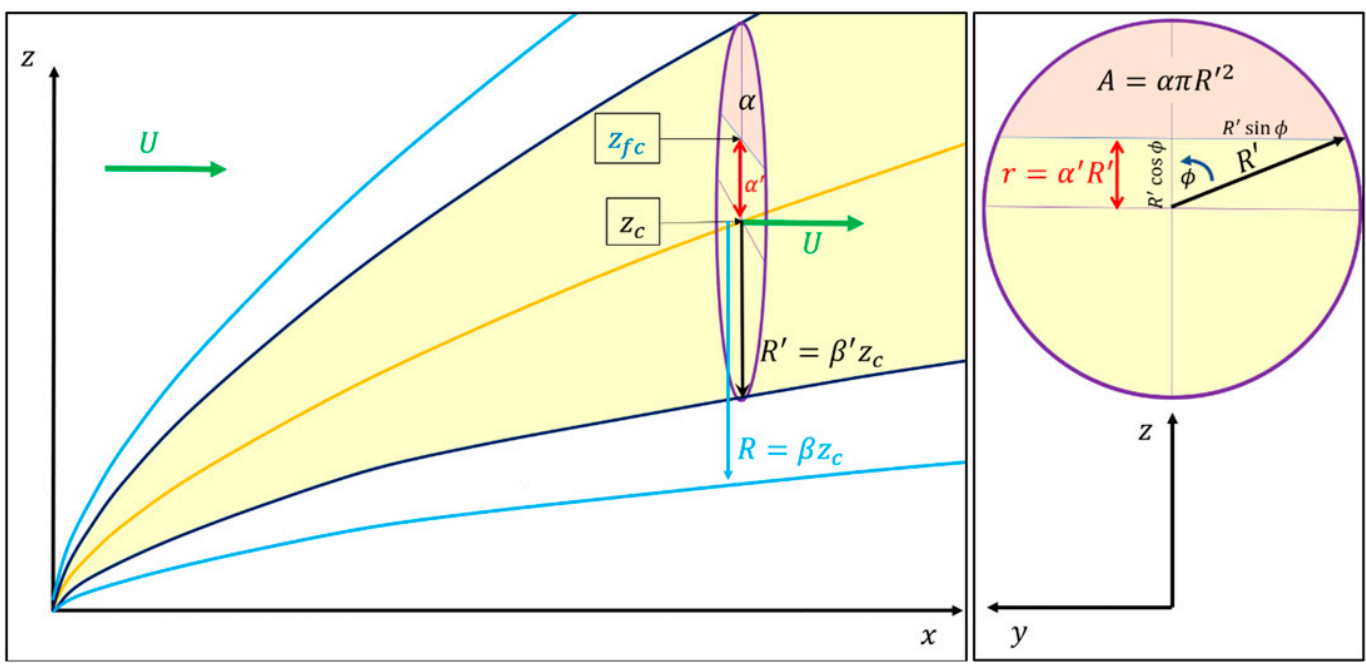

FIG. 2. Schematic representation of a Briggs plume, bent over in the downwind direction $x$ by a constant horizontal wind $U$. The internal plume (yellow shading) has a vertical circular cross section about the plume centerline height $z_{c}$ (yellow line) of radius $R^{\prime}$, which is linearly proportional to the plume centerline height via the constant internal plume entrainment parameter $\beta^{\prime}$. Similarly, the dynamic plume (inside the pale blue lines) is defined by the dynamic plume radius and entrainment rate, $R$, and $\beta$. Only a fraction $\alpha$ of the plume cross-sectional area is required to exceed the free-convection height $z_{\mathrm{fc}}$. The distance between $z_{c}$ and $z_{\mathrm{fc}}$ is expressed as a fraction $\alpha^{\prime}$ of $R^{\prime}$. The method for determining $\alpha^{\prime}$ from $\alpha$ is described in appendix $\mathrm{C}$.

The entrainment parameters have been measured in numerous observational and laboratory studies, with Briggs $(1975,1984)$ concluding they should be set to $\beta=0.6$ and $\beta^{\prime}=0.4$. Limited derivations of these equations are provided in section 3 and appendix A. See Briggs $(1975,1984)$ for a more complete derivation. Descriptions of all the variables used in this paper are provided in Table 1.

When conditions deviate from constant $U$ and neutral stratification, the assumption of a plume with Briggs-like geometry becomes less accurate. However, as shown in the next section, the PFT only needs Briggs's equations to express the plume-buoyancy variation with height, in the "dry-plume layer" between the surface and $z_{\mathrm{fc}}$. The actual plume geometry is not especially important, as long as it captures reasonably well the difference in plume buoyancy between the top and bottom of this layer, and since the buoyancy change is a function of entrainment, the equations need only represent the net entrainment in the layer. To minimize errors associated with the assumed constant $U$ and neutral stratification, $U$ is expressed as an average horizontal wind over the plume depth, and the constant environment potential temperature $\theta_{\mathrm{env}}$ is specified as a representative potential temperature of the dry-plume layer. These choices result in over and underrepresentation of plume buoyancy as the plume ascends, leading to a partial cancellation of errors by the time the plume reaches $z_{\mathrm{fc}}$.

A final important point of difference between the Briggs plume and a wildfire plume is the shape and variation in intensity of the heat source. Figure 2 shows the Briggs's plume has a point source, whereas wildfires have finite heat sources with substantial variation in areal geometry. However, smoke-plume elements are often observed to merge and contract into a single circular neck (e.g., Baum and McCaffrey 1989; Trelles et al. 1999; Kaye and Hunt 2009, see also the discussion in Tory 2018, 19-21), above which the plume is well described by the Briggs equations (e.g., Fig. 4a of Lareau and Clements 2017). Figure 3 shows a photo of the Elephant Hill fire in which an upscale cascade of hundreds of finger-like plumes merge into fewer and fewer larger plumes, culminating in a single approximately circular neck. Tory (2018, p. 20) speculates that the height of the circular neck above the surface is likely to be similar to the distance between the point heat source and an equivalent circle in the Briggs plume. To the extent that this speculation is valid, the Briggs equations could be used to approximate real fire plumes without the need to adjust the height for different fire sizes and surface geometries. This assumption is used in this paper to maximize simplicity and transparency. The shape of the surface heat flux may become important for very linear heat sources (Badlan et al. 2019); however, pyroCb typically, or perhaps always, occur in "deep-flaming" events (McRae et al. 2015) characterized by sustained and intense flaming over a deep area of fire, rather than a linear fire line.

\section{Briggs's model}

The Briggs plume rise model is a bulk plume model where analytic solutions are found after making two additional approximations. The bulk quantities are integrated over vertical circular cross sections $^{3}$ through the plume (Fig. 2), and it is assumed that the bulk plume horizontal flow advects with the background wind. These two approximations greatly simplify the flux equations,

\footnotetext{
${ }^{3}$ Numerical solutions to the flux equations using a circular cross section perpendicular to the plume axis, rather than the Briggs vertical circular cross section, show only minor differences in plume centerline very close to the heat source (not shown).
} 
TABLE 1. List of variables.

\begin{tabular}{|c|c|c|}
\hline$z$ & $\mathrm{~m}$ & Height above plume source \\
\hline$x$ & $\mathrm{~m}$ & Downwind distance from plume source \\
\hline$z_{c}$ & $\mathrm{~m}$ & Briggs's plume centerline height \\
\hline$R, R^{\prime}$ & $\mathrm{m}$ & Dynamic and internal plume radii \\
\hline$b, b^{\prime}$ & $\mathrm{ms}^{-2}$ & Dynamic and internal plume buoyancy \\
\hline$U$ & $\mathrm{~ms}^{-1}$ & Constant horizontal wind speed \\
\hline$U_{\mathrm{ML}}$ & $\mathrm{ms}^{-1}$ & Average mixed-layer horizontal wind speed \\
\hline$V_{\text {flux }}$ & $\mathrm{m}^{3} \mathrm{~s}^{-1}$ & Plume volume flux \\
\hline$m_{\text {flux }}$ & $\mathrm{kg} \mathrm{s}^{-1}$ & Plume mass flux \\
\hline$M_{V \text { flux }}$ & $\mathrm{kg} \mathrm{ms} \mathrm{s}^{-2}$ & Plume vertical momentum flux \\
\hline$B_{\text {flux }}$ & $\mathrm{m}^{4} \mathrm{~s}^{-3}$ & Plume buoyancy flux \\
\hline$H_{\text {flux }}$ & $\mathrm{W}$ & Plume heat flux \\
\hline$V_{\text {ent }}$ & $\mathrm{ms}^{-1}$ & Plume entrainment velocity \\
\hline$\rho_{0}$ & $\mathrm{~kg} \mathrm{~m}^{-3}$ & Plume and environment constant density (Boussinesq approximation) \\
\hline$P$ & $\mathrm{~Pa}$ & Plume pressure \\
\hline$P_{c}$ & $\mathrm{~Pa}$ & Plume centerline pressure \\
\hline$T$ & $\mathrm{~K}$ & Plume temperature \\
\hline$w$ & $\mathrm{~ms}^{-1}$ & Plume vertical velocity \\
\hline$\Delta H$ & $\mathrm{~J} \mathrm{~m}^{-3}$ & Combustion energy per unit volume of plume gas \\
\hline$\Delta T$ & $\mathrm{~K}$ & Plume temperature in excess of the environment temperature \\
\hline$\theta_{\mathrm{pl}}$ & $\mathrm{K}$ & Internal plume potential temperature \\
\hline$\theta_{a}$ & $\mathrm{~K}$ & Potential temperature of the atmosphere \\
\hline$q_{a}$ & $\mathrm{~g} \mathrm{~kg}^{-1}$ & Specific humidity of the atmosphere \\
\hline$\theta_{0}$ & $\mathrm{~K}$ & Reference potential temperature \\
\hline$\theta_{\text {env }}$ & $\mathrm{K}$ & Environment potential temperature (constant atmospheric potential temperature in the plume environment) \\
\hline$\Delta \theta$ & $\mathrm{K}$ & Difference between internal plume and environment potential temperature \\
\hline$l_{b}$ & $\mathrm{~m}$ & Buoyancy length scale \\
\hline$z_{\text {con }}$ & $\mathrm{m}$ & Hypothetical plume condensation height \\
\hline$x_{\text {con }}$ & $\mathrm{m}$ & Downstream distance from the plume source to where $z_{c}=z_{\mathrm{con}}$ \\
\hline$z_{\mathrm{fc}}$ & $\mathrm{m}$ & Free-convection height \\
\hline$\theta_{\mathrm{pl}, \mathrm{fc}}$ & $\mathrm{K}$ & Internal plume potential temperature at the free-convection height \\
\hline$\Delta \theta_{\mathrm{fc}}$ & $\mathrm{K}$ & $\Delta \theta$ at the free-convection height \\
\hline PFT & $\mathrm{W}(\mathrm{GW})$ & Pyrocumulonimbus firepower threshold \\
\hline$\theta_{\mathrm{ML}}$ & $\mathrm{K}$ & Mixed-layer potential temperature \\
\hline$q_{\mathrm{ML}}$ & $\mathrm{g} \mathrm{kg}^{-1}$ & Mixed-layer specific humidity \\
\hline$\beta_{T 18}$ & & The $\beta$ term used in Tory et al. (2018), $\left(=\Delta \theta_{\mathrm{fc}} / \theta_{\mathrm{ML}}\right)$ \\
\hline$\theta_{e, \min }$ & $\mathrm{K}$ & $\begin{array}{l}\text { Minimum equivalent potential temperature warmer than the environment everywhere between the SP curve } \\
\text { and the electrification level }\end{array}$ \\
\hline$\delta \theta_{b}$ & $\mathrm{~K}$ & Buoyancy buffer added to $\theta_{e, \text { min }}$ to account for buoyancy losses from evaporation in the pyro-cloud \\
\hline
\end{tabular}

by reducing the flux velocity to the constant horizontal wind $U$ (Briggs 1975, 1984). The constants introduced in the remainder of this section are listed in Table 2.

\section{a. Briggs's plume flux equations}

For a vertical, circular cross section through the Briggs plume (e.g., Fig. 2) the volume flux is the product of the cross-sectional area and the flow perpendicular to the cross section $(U)$ :

$$
V_{\text {flux }}=\pi R^{2} U \text {. }
$$

The mass flux $m_{\text {flux }}$ is the product of $V_{\text {flux }}$ and density $\rho_{0}$, the vertical momentum flux $M_{V_{\text {flux }}}$ is the product of the mass flux and plume ascent velocity $w$, the buoyancy flux $B_{\text {flux }}$ is the product of $V_{\text {flux }}$ and the plume buoyancy $b$, and the heat flux $H_{\text {flux }}$ is the product of $V_{\text {flux }}$ and the excess heat per unit volume $\Delta H$ :

$$
\begin{gathered}
m_{\text {flux }}=\rho_{0}\left(\pi R^{2} U\right), \\
M_{V_{\text {flux }}}=\rho_{0}\left(\pi R^{2} U\right) w,
\end{gathered}
$$

$$
\begin{aligned}
& B_{\text {flux }}=\left(\pi R^{2} U\right) b, \\
& H_{\text {flux }}=\left(\pi R^{2} U\right) \Delta H,
\end{aligned}
$$

where

$$
b=g \frac{\theta_{\mathrm{pl}}-\theta_{a}}{\theta_{0}}=g \frac{\Delta \theta}{\theta_{0}},
$$

is a Boussinesq form of the buoyancy equation, in which the water vapor contribution to the plume buoyancy is assumed to be negligible ${ }^{4} g$ is the acceleration due to gravity; and $\theta_{\mathrm{pl}}$ and $\theta_{a}$ are the plume and atmospheric potential temperature, respectively; $\theta_{0}$ is a reference potential temperature that could be either $\theta_{\mathrm{pl}}$ or $\theta_{a}$ (or anything in between); and $\Delta \theta$ is the difference between the

\footnotetext{
${ }^{4}$ Errors are $<0.5 \%$ for specific humidity $<8 \mathrm{~g} \mathrm{~kg}^{-1}$, which would be typical for plumes near the condensation level where the buoyancy is calculated.
} 


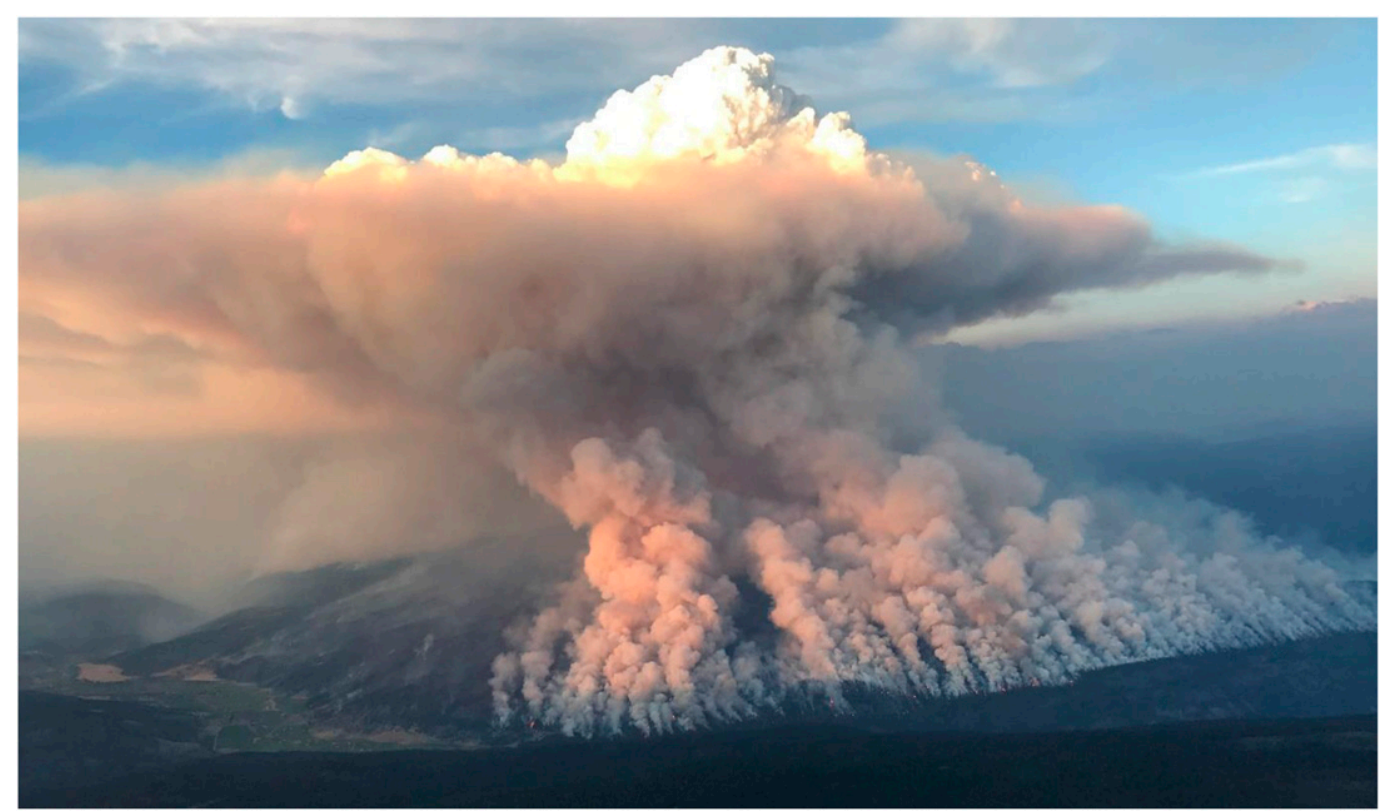

FIG. 3. The Elephant Hill Fire, illustrating plume upscale cascade and "necking." (Photo: Paul Simakoff Ellims).

plume and atmosphere potential temperature. The term $\Delta H$ is the dry static energy difference between the plume and the environment per unit volume. In a neutral atmosphere:

$$
\Delta H=\rho_{0} C_{p d} \Delta \theta
$$

where $C_{p d}$ is the specific heat of dry air at constant pressure. See appendix B for the $\Delta H$ derivation.

Mass entrained into the plume is expressed as a linear flux around the circumference of the circular cross section at an influx or entrainment velocity $V_{\text {ent }}$, linearly proportional to $w$ $\left(V_{\text {ent }}=\beta w\right)$ so that the volume-flux change with downwind distance $x$ is

$$
\frac{d V_{\mathrm{flux}}}{d x}=\frac{d}{d x}\left(\pi R^{2} U\right)=2 \pi R \beta w .
$$

The variation in buoyancy along the plume is caused by: (i) entrained $\theta_{a}$ that dilutes $\theta_{\mathrm{pl}}$, and (ii) variations in $\theta_{a}$ that the plume rises through, which affects the plume-atmosphere potential temperature difference [numerator of Eq. (9)]:

$$
\frac{d B_{\text {flux }}}{d x}=\pi R^{2} N^{2} w
$$

where $N^{2}=\left(g / \theta_{0}\right)\left(\partial \theta_{a} / \partial z\right)$ is the square of the Brunt-Väisälä frequency. In a neutral environment $\theta_{a}=\theta_{\text {env }}=$ constant, and thus $N^{2}=0$ and $B_{\text {flux }}$ is constant [Eq. (12)], which eliminates cause ii of plume buoyancy variation. A constant $B_{\text {flux }}$ in Eq. (7) shows that entrainment expanding the plume crosssectional area $\pi R^{2}$ must also dilute the bulk plume buoyancy $b$.

The vertical momentum flux is dependent on the vertical acceleration provided by the plume buoyancy:

$$
\frac{d\left(\rho_{0} V_{\text {flux }} w\right)}{d x}=\rho_{0} \pi R^{2} b=\rho_{0} \frac{B_{\text {flux }}}{U} .
$$

Equations (11) and (13) are then used to derive the Briggs plume centerline height equation [Eq. (1)] in appendix A.

TABLE 2. List of constants.

\begin{tabular}{ll}
\hline \hline$\pi=3.14159265$ & Circle circumference to diameter ratio \\
$C_{p d}=1005.7 \mathrm{~J} \mathrm{~kg}^{-1} \mathrm{~K}^{-1}$ & Specific heat of dry air \\
$R_{d}=287.04 \mathrm{~J} \mathrm{~kg}^{-1} \mathrm{~K}^{-1}$ & Gas constant for dry air \\
$\kappa=R_{d} / C_{p d}=0.2854$ & Ratio of the gas constant to specific heat for dry air \\
$\alpha^{\prime}=0.32$ & Fraction of plume radius below $z_{\mathrm{fc}}$ \\
$\beta=0.6$ & Dynamic plume entrainment parameter \\
$\beta^{\prime}=0.4$ & Internal plume entrainment parameter \\
$g=9.8 \mathrm{~m} \mathrm{~s}^{-2}$ & Gravitational constant \\
$P_{0}=10^{5} \mathrm{~Pa}$ & Reference pressure \\
$\phi=6.67 \times 10^{-5} \mathrm{~kg} \mathrm{~kg}^{-1} \mathrm{~K}^{-1}$ & Ratio of moisture to temperature increment released by the fire. This value represents a \\
& 15-K temperature increment per $1 \mathrm{~g}$ kg ${ }^{-1}$ specific humidity increment. \\
$\left.\pi C_{p d}\left(\frac{\beta^{\prime}}{1+\alpha^{\prime} \beta^{\prime}}\right)^{2}\right]=397.3 \mathrm{~J} \mathrm{~kg} \mathrm{Kg}^{-1} \mathrm{~K}^{-1}$ & Constant component of the PFT equation [Eq. (25)] \\
$\rho_{0}=0.755 \mathrm{~kg} \mathrm{~m}^{-3}$ & \\
\hline
\end{tabular}


These flux and flux-gradient equations are valid for both the dynamic and internal plumes. Simply replace the dynamic plume quantities $R, \beta$, and $b$ with the internal plume quantities $R^{\prime}, \beta^{\prime}$, and $b^{\prime}$ to get equivalent internal plume equations. ${ }^{5}$

The Briggs equations assume a constant environment potential temperature $\theta_{\text {env }}$ and the SP curve calculations (Tory et al. 2018) assume constant $\theta_{\text {env }}$ and constant specific humidity $q_{\text {env }}$. To calculate PFT in environments that are not well mixed, suitable approximations for these quantities are made. Mixed-layer values $\left(\theta_{\mathrm{ML}}\right.$ and $\left.q_{\mathrm{ML}}\right)$ are chosen to represent the average $\theta_{a}$ and $q_{a}$ entrained into the plume during the ascent to the mixed-layer lifting condensation level. To incorporate the variable mass entrainment rate with height (or pressure if the model data are on pressure levels), vertical gradients of the plume mass-flux equations need to be considered. Equation (11) can be expressed as a vertical gradient using the relationship $d x / d z=U / w$ :

$$
\frac{d\left(\pi R^{2} U\right)}{d z}=2 \pi R \beta U
$$

Combining Eqs. (14) and (2), and making use of the hydrostatic equation, $\partial P / \partial z=-\rho_{0} g$ :

$$
\frac{d\left(m_{\mathrm{flux}}\right)}{d z}=2 \rho_{0} \pi \beta^{2} z_{c} U
$$

and

$$
\frac{d\left(m_{\mathrm{flux}}\right)}{d P}=-\frac{2 \pi \beta^{2}}{g} z_{c} U .
$$

Equations (15) and (16) show that the entrained mass flux increases linearly with plume centerline height, suggesting that the calculation of $\theta_{\mathrm{ML}}$ and $q_{\mathrm{ML}}$ that best represents the mean $\theta_{a}$ and $q_{a}$ entrained into the plume would be average values weighted linearly with height.

\section{b. Plume behavior insight from the Briggs equations}

Useful insight into plume geometry can be obtained from Eq. (1) and its horizontal gradient:

$$
\frac{d z_{c}}{d x}=\frac{2}{3} \frac{z_{c}}{x}=\frac{2}{3}\left[\left(\frac{3}{2 \beta^{2}}\right) \frac{B_{\mathrm{flux}}}{\pi U^{3}}\right]^{1 / 3} x^{-1 / 3} .
$$

These equations show that $U$ and $B_{\text {flux }}$ are the only variable quantities that determine the plume centerline height and slope at a given downstream distance $x$. Together they define the buoyancy length scale:

$$
l_{b}=\frac{B_{\mathrm{flux}}}{\pi U^{3}}
$$

in which the plume centerline height [Eq. (1)] and slope [Eq. (17)] are proportional to $\sqrt[3]{l_{b}}$. Thus, as $l_{b}$ increases, the plume becomes more upright. Figure 4 provides a graphical

\footnotetext{
${ }^{5}$ By definition the heat is contained within the internal plume; hence, the bulk dynamic-plume buoyancy is more dilute than the bulk internal-plume buoyancy, such that $b=\left(\beta^{\prime} / \beta\right)^{2} b^{\prime}$.
}

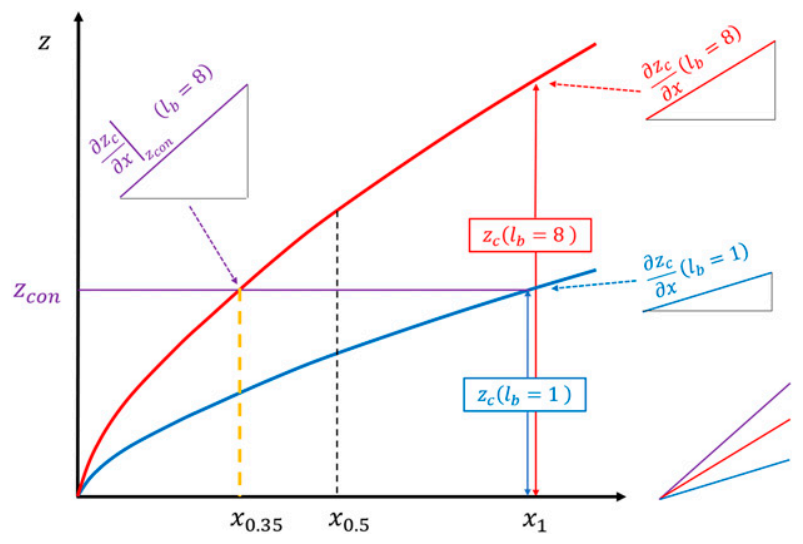

FIG. 4. Schematic illustration of Briggs's plume centerline height $z_{c}$ variability due to changes in the buoyancy length scale $l_{b}$. The vertical and horizontal axes represent height $z$ and downwind distance $x$, respectively. The blue and red curves represent plume centerline heights for plumes with $l_{b}=1$ and 8 arbitrary units, respectively. The corresponding plume heights and slopes at $x=x_{1}$ are labeled. The height $z_{\text {con }}$ is an arbitrary condensation height discussed in the text, which is equal to $z_{c}$ for $l_{b}=1$ at $x=x_{1}$. The same height for the $l_{b}=8$ plume occurs about 0.35 times closer to the origin (yellow dashed line) and is almost 3 times steeper than the $l_{b}=1$ plume at the same height. The plume centerline slope tangents for the three cases are overlaid for comparison in the lower-right corner of the figure.

depiction of this relationship, comparing $l_{b}=1$ and $l_{b}=8$ arbitrary units, which doubles the plume centerline height and slope at a given downstream position.

Equation (18) also shows that the plume centerline height and slope are much more sensitive to changes in the wind than changes in firepower. ${ }^{6}$ For example, to double the plume height and slope at a given $x$ would require the wind speed to be halved, whereas it would require the firepower to be increased 8 times. This suggests that observed fluctuations in plume height and slope, in the absence of any dramatic change in firepower, are likely to be associated with variations in wind speed. Of course, wind speed induced plume fluctuations may be subject to a negative feedback if any corresponding increase (decrease) in surface wind speed increases (decreases) the firepower.

For moist pyro-convection a focus on the condensation height $z_{\text {con }}$ is useful, especially if the thermodynamic environment is relatively steady over time scales in which the wind and firepower vary more frequently. Fixing $z_{c}=z_{\text {con }}$ and making $z_{\text {con }}$ the subject of Eq. (17):

$$
z_{\mathrm{con}}=\left.\frac{3}{2} x_{\mathrm{con}} \frac{d z_{c}}{d x}\right|_{z_{\mathrm{con}}},
$$

shows that any increase in plume slope at $z_{c}=z_{\text {con }}$ must be accompanied by a reduction in $x_{\text {con }}$, i.e., increasing $l_{b}$ causes the plume to become more upright $\left(d z_{c} /\left.d x\right|_{z_{\text {con }}}\right.$ increases $)$ and the

\footnotetext{
${ }^{6}$ For this exercise, buoyancy flux, heat flux, and firepower, can be used interchangeably because they are approximately proportional to one another.
} 
condensing part of the plume moves closer to the fire $\left(x_{\mathrm{con}}\right.$ decreases), with potentially important implications for plumefire feedbacks. The fireward shift of $x=x_{\text {con }}$ and plume-slope increase at $z_{c}=z_{\text {con }}$ is illustrated in Fig. 4 . These changes can be quantified by expressing $x$ as a function of $z_{\text {con }}$ using Eq. (1):

$$
x_{\mathrm{con}}=z_{\mathrm{con}}^{3 / 2}\left[\left(\frac{3}{2 \beta^{2}}\right) l_{b}\right]^{-1 / 2},
$$

and substituting Eq. (20) into Eq. (17):

$$
\left.\frac{d z_{c}}{d x}\right|_{z_{\mathrm{con}}}=\left[\left(\frac{2}{3 \beta^{2}}\right) \frac{l_{b}}{z_{\mathrm{con}}}\right]^{1 / 2} .
$$

Here, $x_{\text {con }} \propto l_{b}^{-1 / 2}$ and $d z_{c} /\left.d x\right|_{z_{\text {con }}} \propto l_{b}^{1 / 2}$. Thus, increasing $l_{b}$ eightfold to double the plume slope and height at a fixed downstream position, results in an almost tripling $(\sqrt{8} \sim 2.83)$ of the plume slope at $z_{\text {con }}$, and brings $x_{\text {con }}$ almost 3 times closer to the fire.

In addition to the above changes to the plume geometry, variations in $l_{b}$ have an impact on the internal plume buoyancy at $z_{\text {con }}$, which can be determined from Eqs. (7) and (2):

$$
b=\frac{B_{\text {flux }}}{\pi\left(\beta z_{\text {con }}\right)^{2} U} .
$$

Importantly, at a given height $z_{\mathrm{con}}, b$ is proportional to $B_{\mathrm{flux}} / U$, whereas $d z_{c} /\left.d x\right|_{z}$ is proportional to $\left(B_{\text {flux }} / U^{3}\right)^{1 / 2}$, and $x_{\text {con }}$ is proportional to $\left(B_{\text {flux }} / U^{3}\right)^{-1 / 2}$. This means changes to $B_{\text {flux }}$ and $U$, that increase the plume slope and proximity to the fire at $z_{\mathrm{con}}$, will in general increase the internal plume buoyancy at $z_{\text {con }}$. However, exceptions are possible when the changes to $B_{\text {flux }}$ and $U$ contribute to opposing tendency changes. For example, tripling $B_{\text {flux }}$ and doubling $U$ produces a $50 \%$ increase in internal plume buoyancy, but a $40 \%$ reduction in plume slope at $z_{\text {con. }}{ }^{7}$ Given such combinations of changes are a relatively small subset of possible changes, a general rule of thumb for the relationship between plume buoyancy and slope can be made: A steeper plume at a given height is likely to be more buoyant than a flatter plume at that height. An additional rule of thumb that can be determined from Eqs. (21) and (22) is as follows: the buoyancy of a plume at $z_{\text {con }}$ in a stronger background wind will be much greater than a plume with the same slope in a lighter background wind.

These results have important implications for interpreting the potential behavior of plumes that are beginning to produce pyrocumulus. If at the cloud base the plume angle is nearly horizontal, then the cloud is relatively far from the fire and the plume buoyancy will be relatively small. If on the other hand the plume angle is relatively steep (especially in strong winds) then the cloud will be closer to the fire, the plume buoyancy will likely be considerably stronger, and the plume will also have

\footnotetext{
${ }^{7}$ More generally, if $U$ increases (decreases) and $B_{\text {flux }}$ increases (decreases) by a greater amount, but less than the cube of the change in $U$, an increase (decrease) in buoyancy will be accompanied by a decrease (increase) in plume slope and proximity to the fire at $z_{\text {con }}$.
}

greater potential to penetrate any stable layer that might be present above the condensation level.

\section{Pyrocumulonimbus firepower threshold}

In a neutral atmosphere entrainment does not add heat to the plume, thus the sensible heat flux from combustion entering the plume ${ }^{8}$ can be determined from the heat flux on any plume cross section down wind of the heat source. This heat flux can be expressed as a function of measurable quantities on an internal plume cross section (e.g., see Fig. 2), using Eqs. (3), (8), and (10):

$$
H_{\text {flux }}=\pi\left(\beta^{\prime} z_{c}\right)^{2} U \rho_{0} C_{p d} \Delta \theta
$$

If it is known how high a plume must rise and how buoyant the plume needs to be at that height for a pyroCb to develop, and, if an average wind speed the plume must rise through can be estimated, then Eq. (23) can be used to estimate the minimum heat flux or fire power required for pyroCb development. We propose that this quantity is the simplest form of PFT that captures the necessary plume-rise physics, which, as noted in section 1 , represents an estimate of the minimum firepower required for pyroCb to form in any given atmospheric environment.

Using $z_{c}$ directly in Eq. (23) implies that half the plume cross section has exceeded $z_{c}$ and that the plume top is actually $\beta^{\prime} z_{c}$ higher than $z_{c}$ [(i.e., $40 \%$ higher than $z_{c}$, Eq. (3)]. A more appropriate assumption is that some smaller fraction of the plume cross-section area $\alpha$ needs to exceed the free-convection height $z_{\text {fc }}$ (Fig. 2). It is simpler to represent this fraction as a plume radius fraction $\alpha^{\prime}$ in the PFT calculation, such that $z_{\mathrm{fc}}=z_{c}+$ $R^{\prime} \alpha^{\prime}$ (Fig. 2). Then using Eq. (3):

$$
z_{c}=\frac{z_{\mathrm{fc}}}{1+\alpha^{\prime} \beta^{\prime}} \text {. }
$$

A method for determining $\alpha^{\prime}$ from $\alpha$ is described in appendix $\mathrm{C}$.

The PFT equation is obtained by substituting Eq. (24) into Eq. (23), and arranged into constant and variable components:

$$
\mathrm{PFT}=\left[\pi C_{\mathrm{pd}}\left(\frac{\beta^{\prime}}{1+\alpha^{\prime} \beta^{\prime}}\right)^{2}\right] \rho_{0} z_{\mathrm{fc}}^{2} U_{\mathrm{ML}} \Delta \theta_{\mathrm{fc}} .
$$

The fc subscript has been added to $\Delta \theta$, because it is diagnosed at the free-convection height (i.e., $\Delta \theta_{\mathrm{fc}}=\theta_{\mathrm{pl}, \mathrm{fc}}-\theta_{\mathrm{ML}}$ ), and the ML subscript has been added to $U$ to indicate a mixed-layer average is required in practice. The term $\rho_{0}$ represents the mean density on the vertical plume cross section (depicted in Fig. 2). Thus, using the gas law, $P=$ $\rho_{0} R_{d} T$, and the potential temperature equation, $T=\theta\left(P / P_{0}\right)^{\kappa}$,

\footnotetext{
${ }^{8}$ In this model, it is assumed that most of the radiant heat is emitted in the combustion zone, and that any additional radiant heat loss from the plume is negligible and thus ignored (e.g., Luderer et al. 2009; Tory et al. 2018).
} 
an appropriate $\rho_{0}$ corresponds to the plume centerline temperature and pressure $P_{c}$ :

$$
\rho_{0}=\frac{P_{c}}{R_{d} \theta_{\mathrm{pl}, \mathrm{fc}}}\left(\frac{P_{0}}{P_{c}}\right)^{\kappa} .
$$

To calculate $P_{c}$, it is assumed that the ratio of the free-convection and plume-centerline heights is the same as the ratio of freeconvection and plume centerline pressures above the surface:

$$
\frac{P_{\mathrm{sfc}}-P_{\mathrm{fc}}}{P_{\mathrm{sfc}}-P_{c}}=\frac{z_{\mathrm{fc}}}{z_{c}}=1+\alpha^{\prime} \beta^{\prime},
$$

so that

$$
P_{c}=\frac{P_{\mathrm{fc}}-P_{\mathrm{sfc}}}{1+\alpha^{\prime} \beta^{\prime}}+P_{\mathrm{sfc}} .
$$

\section{a. Insights from the simple PFT}

Before discussing how each term might be calculated, it is worth considering the insight Eq. (25) offers, and we remind the reader that the PFT represents an estimate of the minimum firepower necessary for pyroCb development, which means smaller values favor pyroCb development. The square bracket term is constant for all environments, and $\rho_{0}$ varies minimally compared to the last three terms. These last three terms are responsible for the majority of the PFT variability, and provide very useful insight into pyroCb formation potential. They confirm the intuitive relationships between plume behavior, fire intensity, and atmospheric state:

- The taller the plume needs to be $\left(z_{\mathrm{fc}}\right)$ the greater the fire power required.

- The stronger the horizontal wind $\left(U_{\mathrm{ML}}\right)$ the greater the firepower required to counter the tendency for the plume to tilt over in the wind.

- The greater the capping inversion or stable layer that the plume must penetrate, the larger $\Delta \theta_{\mathrm{fc}}$ must be, and the greater fire power required.

While it is important to have these intuitive relationships confirmed, the greatest value of Eq. (25), is that it quantifies the exponents of each term and their relative relationship to one another. For example, pyroCb very often form in the vicinity of wind changes on days of extreme fire danger: hot, dry, and windy conditions. Hot and dry conditions ensure large $z_{\mathrm{fc}}$, and windy conditions are reflected in large $U_{\mathrm{ML}}$, contributing to considerable PFT even if $\Delta \theta_{\mathrm{fc}}$ is relatively small. A wind change that brings significantly cooler and moister air to the fire ground, produces a dramatic reduction in the square of the free convection height $z_{\mathrm{fc}}^{2}$ contributing to a large reduction in PFT. Experiments with the PFT have shown an order of magnitude reduction in PFT with the passage of a wind change is not uncommon.

While pyroCb formation in the vicinity of wind changes is a common occurrence in southern Australia, and a threat well known to fire weather forecasters and fire behavior analysts, the insight gained by Eq. (25) is new. It complements existing understanding of the relationship between wind changes and pyroCb formation that dramatic increases in fire power results as the wind change transforms a flank fire into a head fire, and increased plume height as frontal lifting helps elevate the plume.

\section{b. Assumptions required to calculate the simple PFT}

The variable terms in Eq. (25) need to be determined to calculate the simple PFT. A set of assumptions are made to ensure a unique solution:

1) The plume behaves like a Briggs plume in a neutral, constant background wind environment. This requires single values of mixed-layer potential temperature $\theta_{\mathrm{ML}}$, specific humidity $q_{\mathrm{ML}}$ and horizontal wind $U_{\mathrm{ML}}$ to be determined that represent the atmospheric column from the surface to the height at which the plume condenses. The mixed-layer lifting condensation level (ML-LCL) is a good approximation for this height.

2) The mixed-layer properties need to reflect the average potential temperature and specific humidity entrained into the plume, thus a weighted average, that incorporates increased entrainment rates with height, is assumed to calculate $\theta_{\mathrm{ML}}$ and $q_{\mathrm{ML}}$ from the environmental temperature and moisture profile.

3) The wind $U$ is set to the magnitude of the average horizontal velocity within the mixed layer.

4) The Tory et al. (2018) saturation point curve, using $\theta_{M L}$ and $q_{\mathrm{ML}}$, and an assumed fire heat to moisture ratio of $15 \mathrm{~K}$ to $1 \mathrm{~g} \mathrm{~kg}^{-1}$, defines the plume condensation properties.

5) After condensing, a plume parcel must remain buoyant (warmer than the environment) while it rises to or beyond the designated minimum cloud-top height. In this PFT a conservative electrification level, corresponding to $-20^{\circ} \mathrm{C}$, was chosen for the cloud top height. ${ }^{9}$ The minimum equivalent potential temperature of a parcel satisfying this criterion is labeled $\theta_{e \text {,min }}$. An arbitrary buoyancy buffer $\left(\delta \theta_{b} \sim\right.$ $0.5-1.0^{\circ} \mathrm{C}$, potential temperature increment to account for buoyancy dilution from entrainment of cooler drier air into the moist plume) is added to $\theta_{e \text {,min }}$ to represent a more realistic free-convection limit. ${ }^{10}$ The height at which this parcel condenses is the minimum free-convection height $z_{\mathrm{fc}}$.

\section{c. Calculation of the simple PFT}

The simple PFT calculation is a multistep process that requires the determination of the five variable quantities in Eqs. (25) and (26). The procedure is illustrated is this subsection using thermodynamic diagrams from the Melbourne soundings on the morning and evening of Black Saturday, 1000 and 2200 LST

\footnotetext{
${ }^{9}$ This cloud-top temperature indicator was chosen to ensure the majority of electrified plumes are captured, as well as other potentially dangerous towering pyrocumulus events.

${ }^{10}$ The pyroCb climatology of Peterson et al. (2017) identifies middle troposphere humidity above the mixed layer as an important indicator of pyroCb formation potential, which suggests the $\delta \theta_{b}$ increment would ideally vary with evaporation potential of entrained air (e.g., the difference in specific humidity between the plume parcel and the environment). Forecasters could perhaps adjust $\delta \theta_{b}$ upward by a few kelvin when the middle troposphere is very dry.
} 


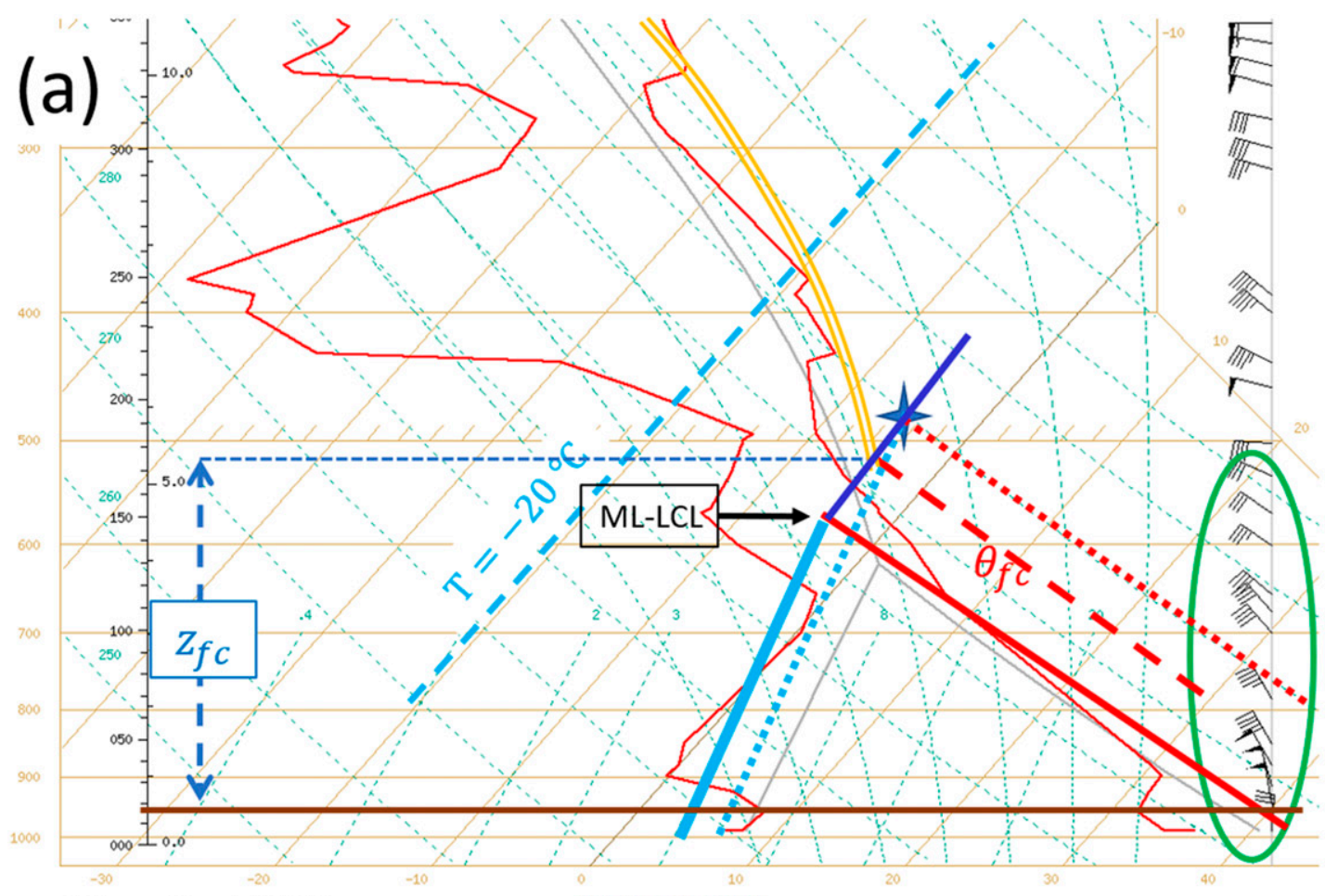

Melbourne Airport (086282)

$06 / 02 / 20092300$ UTC

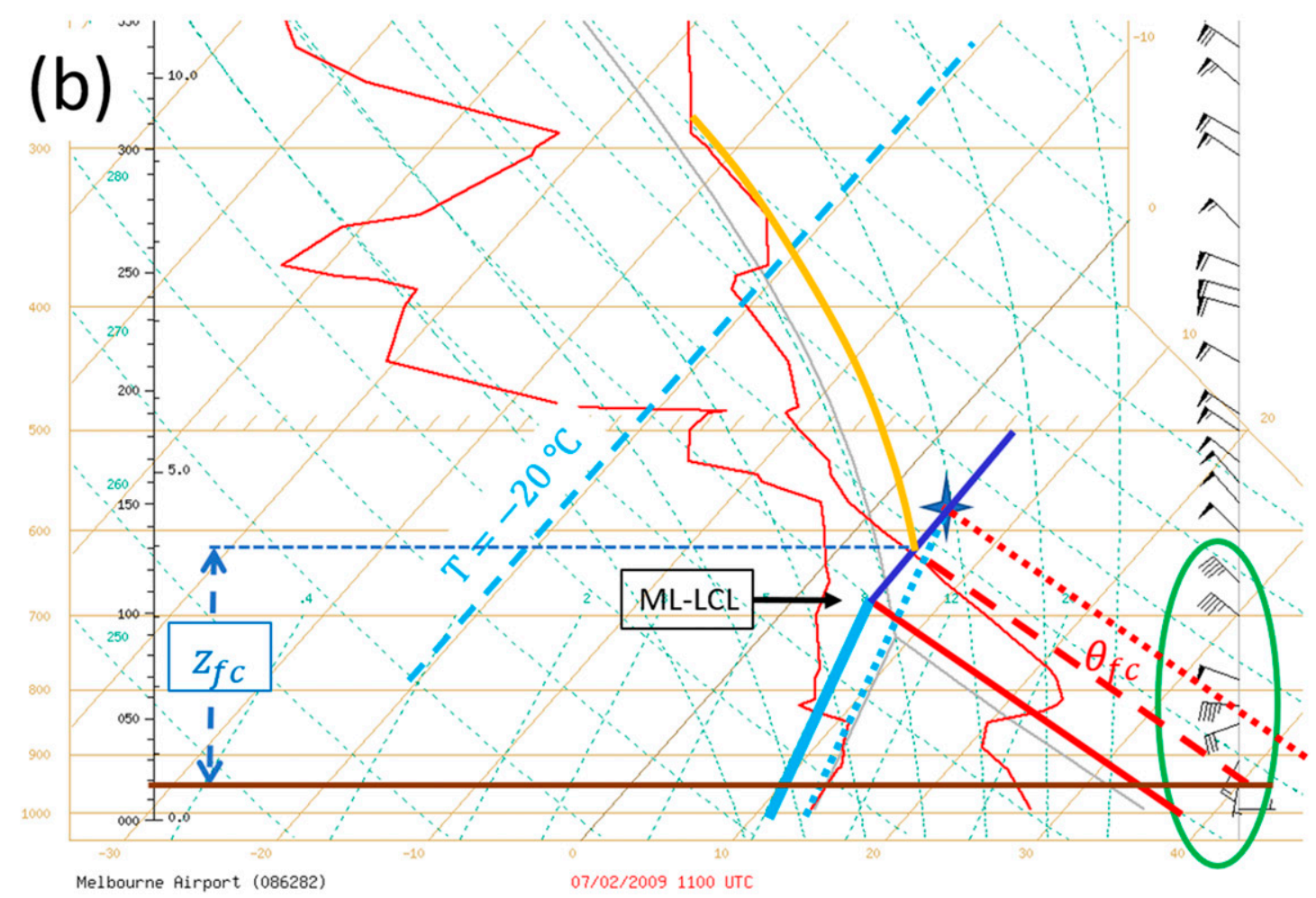

FIG. 5. Illustration of the manual PFT calculation for the Melbourne soundings on Black Saturday (7 Feb 2009), (a) 1000 and (b) $2200 \mathrm{LST}$, described in section $4 \mathrm{c}$. The $z_{\mathrm{fc}}$ estimates are $4.8 \mathrm{~km}$ in (a) and $3.5 \mathrm{~km}$ in (b) after subtracting $0.5 \mathrm{~km}$ for the elevation of the Kinglake and Marysville fires. The $\Delta \theta_{\mathrm{fc}}$ estimates are $9 \mathrm{~K}$ in (a) and $8 \mathrm{~K}$ in (b), and $U_{\mathrm{ML}}$ estimates are $20 \mathrm{~m} \mathrm{~s}^{-1}$ in (a) and $17 \mathrm{~m} \mathrm{~s}^{-1}$ in (b). Corresponding manual PFT estimates yield 1240 and $500 \mathrm{GW}$ in (a) and (b), respectively. In (a) two moist adiabat lines (yellow) are shown close together, where the gap between them represents the arbitrary addition of buoyancy to account for in-plume buoyancy losses due to cooling from evaporation of cloud water by dry air entrained into the plume. 
7 February 2009 (Fig. 5). A manual procedure for estimating the PFT from a thermodynamic diagram is also described here. The principal simplifications in the manual method are that the SP curve is a straight line, $\rho_{0}$ is assigned a constant value, and the remaining terms are estimated from the thermodynamic diagram.

Step 1: Determine $\theta_{\mathrm{ML}}$ (thick red line) and $q_{\mathrm{ML}}$ (thick pale blue line) by taking average values of the environment potential temperature and specific humidity, up to the mixed-layer lifting condensation level (ML-LCL, intersection of the two lines). Begin with a shallow estimate of the ML and increase incrementally until the ML-LCL lies within this estimated ML. Quantities used in the averaging should be weighted to reflect entrainment rates that increase linearly with plume centerline height [Eqs. (15) and (16)]. If calculating manually, estimated averages with a slight bias toward more elevated levels provides a good approximation.

Step 2: Determine a series of saturation points corresponding to small increments of plume buoyancy. With respect to the buoyancy-like parameter of Tory et al. $\left(2018, \beta_{\mathrm{T} 18}=\Delta \theta_{\mathrm{fc}} / \theta_{\mathrm{ML}}\right)$ these increments range from $\beta_{\mathrm{T} 18}=0$ to about 0.1 . The saturation-point potential temperature and specific humidity are linked via $\beta_{\mathrm{T} 18}$, and the assumed ratio of moisture to temperature increments produced by the fire, $\varphi$ :

$$
\begin{aligned}
& \theta_{\mathrm{SP}}=\left(\beta_{\mathrm{T} 18}+1\right) \theta_{\mathrm{ML}}, \\
& q_{\mathrm{SP}}=q_{\mathrm{ML}}+\beta_{\mathrm{T} 18} \varphi \theta_{\mathrm{ML}} .
\end{aligned}
$$

For ease of plotting on a thermodynamic diagram, these saturation points can be defined by their temperature and pressure using Eqs. (14)-(16) of Tory et al. (2018). If calculating manually an approximate SP curve can be constructed by marking an approximate saturation point (Fig. 5, blue star) at the intersection of the $\theta_{\mathrm{ML}}+15 \mathrm{~K}$ adiabat (dotted red line) and the $q_{\mathrm{ML}}+1 \mathrm{~g} \mathrm{~kg}^{-1}$ specific humidity isopleth (dotted pale blue line). A straight line between the ML-LCL and this point provides a good SP curve approximation (Fig. 5, dark blue line).

Step 3: Find the free-convection height $z_{\mathrm{fc}}$. Starting at the MLLCL, proceed along the SP curve to a point where a moist adiabat (left orange line in Fig. 5a) just exceeds the environment temperature everywhere between the SP curve and the $T=-20^{\circ} \mathrm{C}$ minimum cloud-top height (dashed pale blue line). Add the buoyancy buffer $\left(\delta \theta_{b}\right.$, mentioned in assumption 5 above) to find the moist parcel path with added buoyancy to account for buoyancy losses from evaporation of entrained air (right orange line in Fig. 5a). The height above the surface of the intersection between this new moist adiabat and the SP curve is the free-convection height $z_{\mathrm{fc}}$. At present the buoyancy buffer is a small fixed value, which is barely distinguishable on thermodynamic diagrams (e.g., the thin gap between yellow lines in Fig. 5a). Hereafter, a single thicker line is used in subsequent figures. ${ }^{11}$

\footnotetext{
${ }^{11}$ In the future, a variable buoyancy buffer may be introduced that accounts for greater buoyancy losses when moist plumes rise through drier air.
}

Note, the surface height might vary significantly from the base of the height indicator on the thermodynamic diagram, especially if the balloon launch was some distance from the fire.

Step 4: Find $\Delta \theta_{\mathrm{fc}}$ : Subtract $\theta_{\mathrm{ML}}$ (thick solid red line) from $\theta_{\mathrm{pl}, \mathrm{fc}}$ (dashed red line).

Step 5: Find $U_{\mathrm{ML}}$ : in the layer between the surface and $z_{\mathrm{fc}}$, average the meridional and zonal wind components separately and set $U_{\mathrm{ML}}$ to the magnitude of this averaged wind vector. If calculating manually, a visual estimate of the average wind speeds in this layer (green ellipse) is sufficient.

Step 6: Find $P_{c}$ : Use Eq. (28) to determine the plume centerline pressure.

The constant terms in Eq. (25) $\left(\pi, C_{p}, \alpha^{\prime}\right.$, and $\left.\beta^{\prime}\right)$ and Eq. (26) $\left(P_{0}, \kappa, R_{d}\right)$ are listed in Table 2 (Note: experimentation and validation in the future could lead to changes in $\left.\alpha^{\prime}\right)$. While $\rho_{0}$ can be determined manually from the thermodynamic diagram $\left(\theta_{\mathrm{pl}, \mathrm{fc}}\right.$ can be read directly, and $P_{c}$ can be calculated manually by reading the pressure at $z_{\mathrm{fc}}$ to get $P_{\mathrm{fc}}$, and noting an appropriate $P_{\mathrm{sfc}}$ ) it is time consuming and perhaps unnecessary if only a rough PFT estimate is desired. Choosing $\rho_{0}=$ $0.755 \mathrm{~kg} \mathrm{~m}^{-3}$, the product of the square bracketed term and $\rho_{0}$ in Eq. (25) reduces to a round 300. To reduce complexity even further, units of kilometers, meters per second, and kelvin are used for $z_{\mathrm{fc}}, U_{\mathrm{ML}}$, and $\Delta \theta_{\mathrm{fc}}$, respectively, and the constant is divided by 1000 , yielding PFT in units of gigawatts $(\mathrm{GW})$ :

$$
\operatorname{PFT}_{(\mathrm{GW})}=0.3\left(z_{\mathrm{fc}(\mathrm{km})}\right)^{2} U_{\mathrm{ML}\left(\mathrm{ms}^{-1}\right)} \Delta \theta_{\mathrm{fc}(\mathrm{K})} .
$$

(This equation represents a total firepower, and not a firepower per unit area.)

\section{Examples}

In this section, manual PFT analyses from atmospheric soundings relating to four fires are presented using Eq. (31). While $\rho_{0}$ could be estimated using Eqs. (26)-(28) to provide a more accurate PFT estimation, there is limited practical value in calculating PFT to high precision if the firepower estimates have high uncertainty, or do not exist. Furthermore, available soundings may not accurately represent the true atmospheric profile at the fire location when pyroCb form. Targeted balloon launches near fires, could be of high value for accurate PFT estimates. Despite these uncertainties, preliminary comparisons between PFT and firepower estimates for past events and real-time pyroCb prediction made by Musa Kilinc (Country Fire Association, Victoria, Australia) have yielded very encouraging results. This firepower estimation method is presented in appendix D.

Apart from these preliminary efforts, PFT verification has been mainly qualitative. We expect that calculated PFT values will contain both biases and random errors. Random errors could be due to random errors in the input data, while biases might result from inaccuracies in the underpinning assumptions. Assuming that biases due to inaccurate assumptions are reasonably similar between events, useful insight can be gained by considering relative values. Furthermore, comparison with 
PFT values from known events can provide a rough baseline for the comparison. For example, the PFT calculated from a forecast model sounding corresponding to an intense pyroCb that developed during the Sir Ivan Fire (February 2017, New South Wales, Australia) with the passage of a wind change, was about $300 \mathrm{GW}$, when fire danger conditions were extreme. Additional PFT experiments would suggest this might be close to an upper limit for most wildfires, excluding exceptionally large fires such as Chisholm (May 2001, Alberta Canada), Canberra (January 2003, Australian Capital Territory, Australia), Black Saturday (February 2009, Victoria, Australia), and Gospers Mountain (December 2019, New South Wales, Australia).

\section{a. Black Saturday}

The two most destructive fires on Black Saturday occurred within $100 \mathrm{~km}$ of the Melbourne airport radiosonde station. Fire danger conditions were unprecedented due to record high temperatures and very strong and gusty winds. Both fires were ignited on the day and spread rapidly, exhibiting extreme fire behavior, exacerbated by a wind change that transformed long flank fires into head fires tens of $\mathrm{km}$ in width, and the merging of the two fires. PyroCb formed on both fires with associated lightning persisting for more than $7 \mathrm{~h}$. Record spotting distances ( $>30 \mathrm{~km}$, Cruz et al. 2012) and lightning ignition distances ( $>100 \mathrm{~km}$, Dowdy et al. 2017) were recorded.

The two Melbourne Airport soundings on the day were launched at 1000 and 2200 LST (Fig. 5), the former prior to the ignition of both fires and the latter about 4 or $5 \mathrm{~h}$ after the passage of the wind change. The morning sonde shows evidence of a shallow stable layer between the surface and $900 \mathrm{hPa}$ with a deep and well-mixed layer above extending to about $650 \mathrm{hPa}$. In the next few hours, the near-surface stable layer mixed out bringing surface temperatures approaching $48^{\circ} \mathrm{C}$ in the outer southwest of Melbourne, suggesting the mixed layer grew to about $550 \mathrm{hPa}(\sim 5 \mathrm{~km}$ deep). A manual PFT analysis for the $1000 \mathrm{LST}$ sonde (Fig. 5a) yields $1240 \mathrm{GW}$, which is about 4 times greater than the Sir Ivan baseline value, suggesting very unfavorable pyroCb conditions.

The 2200 LST sonde shows a cool change had arrived with a substantial drop in temperature and increased moisture below about $800 \mathrm{hPa}$. The corresponding manual PFT analysis yields $500 \mathrm{GW}$, which is still large compared to the Sir Ivan benchmark, but a substantial reduction compared to the morning value. However, focusing on the $2200 \mathrm{LST}$ trace above $800 \mathrm{hPa}$, and extrapolating the temperature and dewpoint temperature lines to the surface, a manual estimate of the corresponding $z_{\mathrm{fc}}$ is perhaps only a few hundred meters higher and $\Delta \theta_{\mathrm{fc}}$ is much smaller than that shown in Fig. 5b, yielding an estimated PFT just prior to the wind change of about $290 \mathrm{GW}$ (using $z_{\mathrm{fc}}=$ $4 \mathrm{~km}, \Delta \theta_{\mathrm{fc}}=3 \mathrm{~K}$, and $U_{\mathrm{ML}}=20 \mathrm{~m} \mathrm{~s}^{-1}$ ).

This case illustrates a common pattern with pyroCb events investigated so far (not shown), in which the PFT is extreme (very low chance of pyroCb) during the most severe fire danger, when the free-convection height is very large, and it reduces to a minimum value in the hour or so prior to or following a wind change, before increasing again. The first sounding captures the extreme PFT, and the second captures values on the increase again postwind change.
The first lightning strike was recorded at 1650 LST (Dowdy et al. 2017), about $40 \mathrm{~min}$ prior to the arrival of the wind change that dramatically increased the fire size. Lightning activity became more frequent following the wind change and continued for several hours after. The exceptional nature of these fires saw the pyroCb activity continue to at least midnight, two hours after the second sounding, well beyond the expected PFT minimum (and most favorable pyroCb values).

\section{b. Chisholm}

Two manual PFT analyses are presented in Fig. 6 for morning and afternoon soundings from Edmonton Stony Plain (Alberta, Canada) on the day of the Chisholm firestorm, 28 May 2001 (Rosenfeld et al. 2007). The sounding site is about $150 \mathrm{~km}$ south of the fire location, with the afternoon (0000 UTC, Fig. 6b) sounding corresponding to the time of greatest fire intensity and plume activity. The morning sounding shows a shallow nocturnal inversion with a near-isentropic layer extending to about $650 \mathrm{hPa}$. The specific humidity decreases with height, and conditions are very dry above $600 \mathrm{hPa}$. The diagnosed free-convection height is about $3.2 \mathrm{~km}$ (assuming the Chisholm fire location is about $100 \mathrm{~m}$ lower in elevation than the sounding site), and $\Delta \theta_{\mathrm{fc}} \sim 7^{\circ} \mathrm{C}$. Strong south-southeast winds of about $40 \mathrm{kt}\left(1 \mathrm{kt} \approx 0.51 \mathrm{~m} \mathrm{~s}^{-1}\right)$ are evident below $z_{\mathrm{fc}}$, giving $U_{\mathrm{ML}} \sim 20 \mathrm{~m} \mathrm{~s}^{-1}$, and a manual PFT estimate of about $520 \mathrm{GW}$.

At about the time of the morning sounding the estimated fire spread rates and head fire intensities increased rapidly (See Fig. 2.12 of ASRD, 2001), soon exceeding $1 \mathrm{~m} \mathrm{~s}^{-1}$ and $100 \mathrm{MW} \mathrm{m}^{-1}$, respectively. Using this head fire intensity, a head fire of about $5 \mathrm{~km}$ in length would be required to generate enough heat to exceed the $520 \mathrm{GW}$ PFT. ${ }^{12}$

The arrival of a wind-change in the afternoon dramatically increased the fire front to about $25 \mathrm{~km}$ (Rosenfeld et al. 2007) and the head-fire intensity estimates increased further peaking at $130 \mathrm{MW} \mathrm{m}^{-1}$. If representative of the entire head fire, the firepower would have been $3250 \mathrm{GW}$. The wind change brought moister conditions to the fire ground (Fig. 6b), which according to the PFT analysis, reduced $z_{\mathrm{fc}}$ and $\Delta \theta_{\mathrm{fc}}$ significantly, contributing to a fivefold decrease in PFT to about $100 \mathrm{GW}$. This estimated heat flux exceeds the estimated firepower threshold for pyroCb formation in this case by more than 30 times. Drawing on the discussion in section $3 \mathrm{~b}$, upright plumes with substantial buoyancy at condensation, and exceptional values of fireCAPE would be expected, which is consistent with the observed extreme cloud heights and tropopause overshooting of up to $3 \mathrm{~km}$ (Rosenfeld et al. 2007).

\section{c. Bald Fire and Sedgerly Rd Fire: A comparison}

The Bald Fire of Northern California (July 2014) was the subject of a field campaign that used lidar to study the fire plume and mobile radiosondes to measure the thermodynamic profile of the atmosphere the plume was rising through (Lareau

\footnotetext{
${ }^{12}$ This simple calculation ignores radiative heat losses, and additional heat gains from combustion and smoldering behind the head fire and on the flanks, which will partially compensate one another.
} 
71119 WSE Edmonton Stony Plain
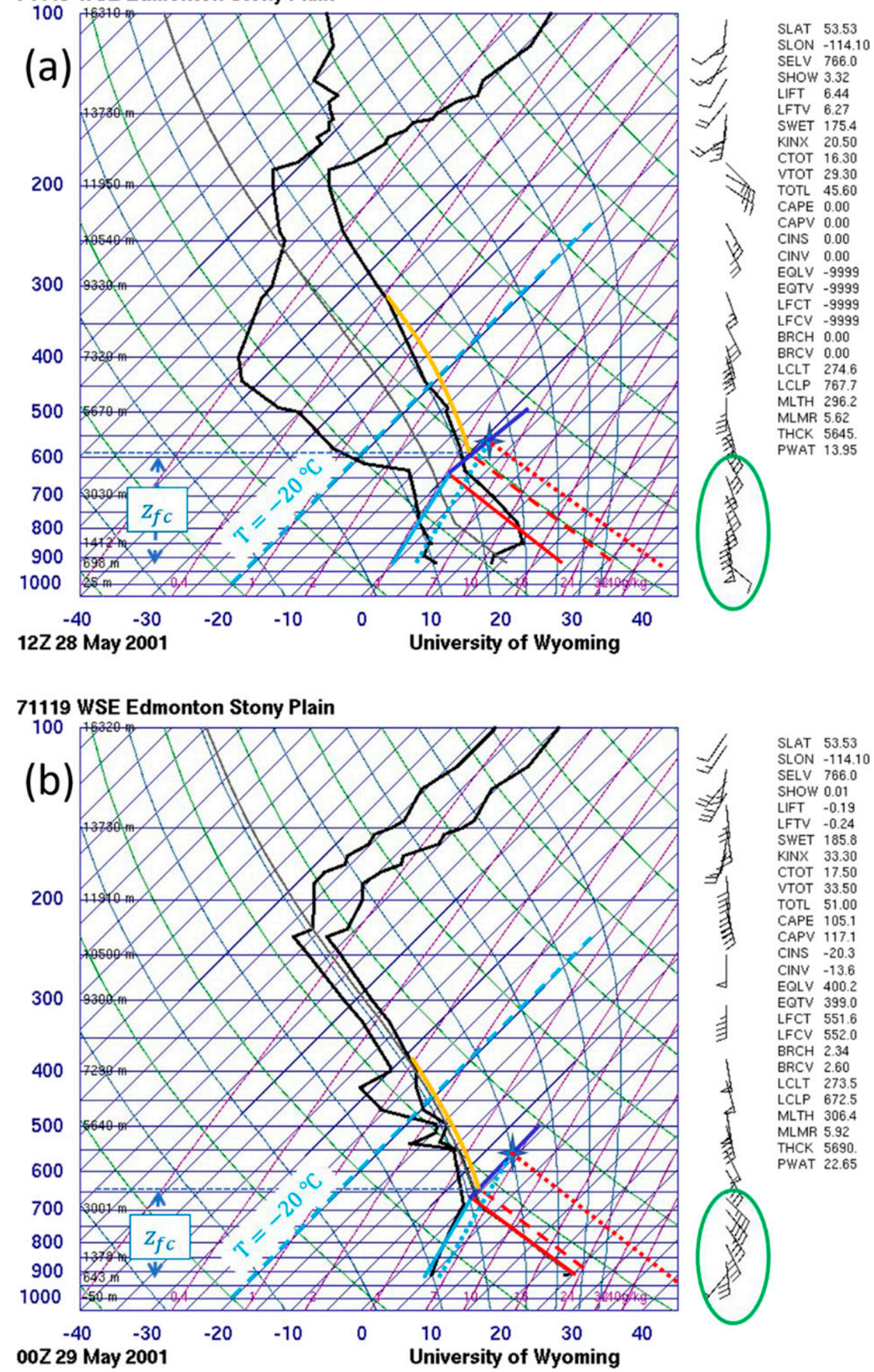

FIG. 6. Manual PFT calculations for the Edmonton soundings on the day of the Chisholm firestorm (28 May 2001), (a) 0600 and (b) 1800 LST. The $z_{\mathrm{fc}}$ estimates are $3.3 \mathrm{~km}$ in (a) and $2.7 \mathrm{~km}$ in (b). The $\Delta \theta_{\mathrm{fc}}$ estimates are $8 \mathrm{~K}$ in (a) and $2.5 \mathrm{~K}$ in (b), and $U_{\mathrm{ML}}$ estimates are $20 \mathrm{~m} \mathrm{~s}^{-1}$ in (a) and $18 \mathrm{~m} \mathrm{~s}^{-1}$ in (b). Corresponding manual PFT estimates yield 520 and $100 \mathrm{GW}$ in (a) and (b), respectively. These soundings were retrieved from http://weather.uwyo.edu/upperair/sounding.html. 

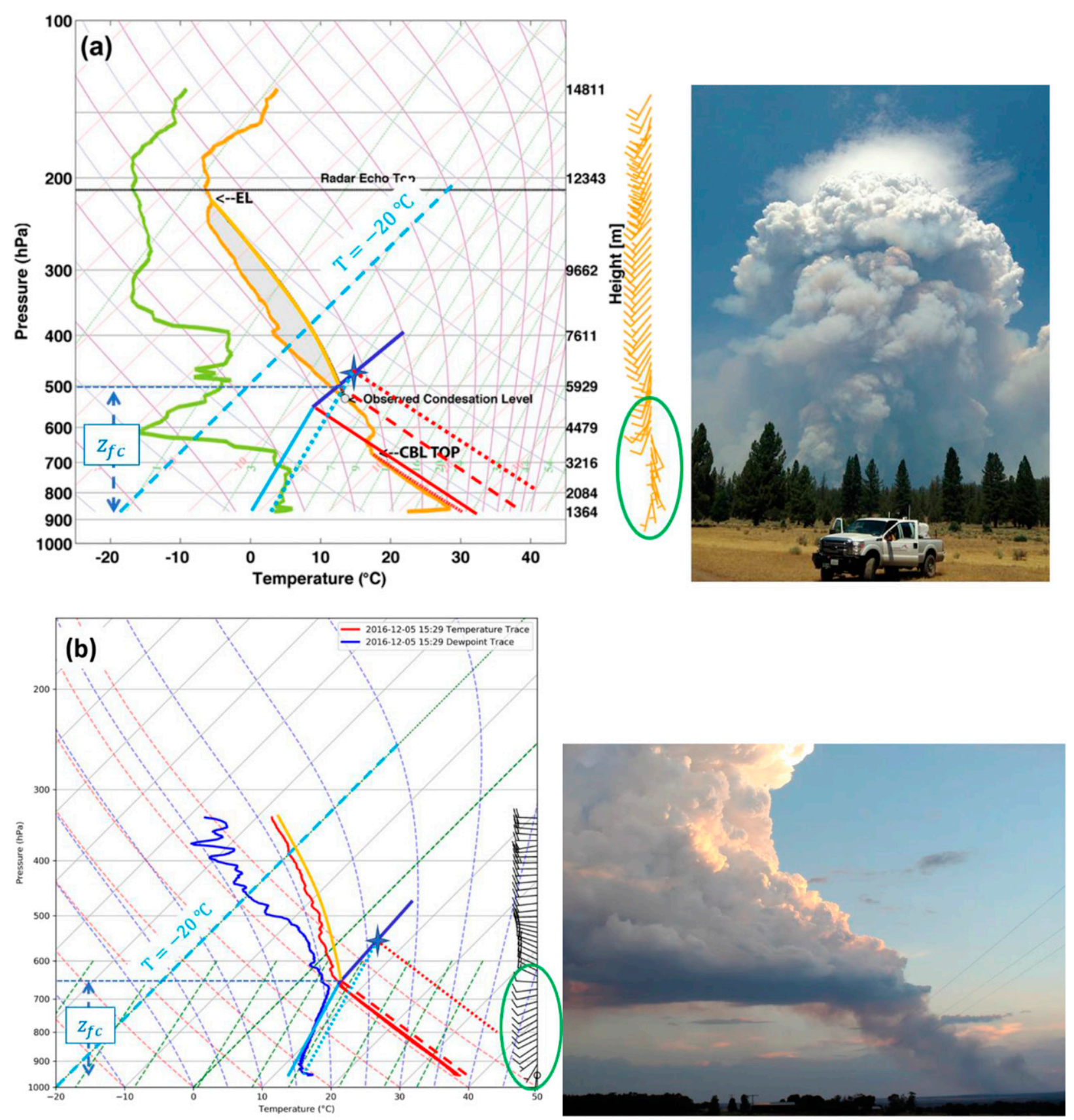

FIG. 7. Manual PFT calculations from radiosondes launched near (a) the Bald Fire (Northern California), at 2100 PDT 2 Aug 2014 and (b) the Sedgerly Rd Fire (near Inglewood, Queensland, Australia) at 1741 Australian eastern standard time (AEST) 5 Dec 2016 . The $z_{\mathrm{fc}}$ estimates are $4.4 \mathrm{~km}$ in (a) and $2.8 \mathrm{~km}$ in (b). The $\Delta \theta_{\mathrm{fc}}$ estimates are $8 \mathrm{~K}$ in (a) and $1 \mathrm{~K}$ in (b), and $U_{\mathrm{ML}}$ estimates are $3 \mathrm{~m} \mathrm{~s}{ }^{-1}$ in (a) and $5 \mathrm{~m} \mathrm{~s}^{-1}$ in (b). Corresponding manual PFT estimates yield 140 and $12 \mathrm{GW}$ in (a) and (b), respectively. The Bald Fire trace and photo are reproduced from Lareau and Clements (2016), and the Sedgerly Rd fire trace and photo were provided by Nick McCarthy.

and Clements 2016). The fire location was about $1000 \mathrm{~m}$ above sea level in the midlatitudes (about $41^{\circ} \mathrm{N}$ ). The Sedgerly $\mathrm{Rd}$ Fire occurred on the opposite side of the Pacific and opposite hemisphere in the subtropics (about $28^{\circ} \mathrm{S}$, near Inglewood, Queensland, Australia, December 2016) at a lower elevation of about $500 \mathrm{~m}$. It was also the subject of a field campaign that included mobile radiosondes to analyze the environment. It is interesting to compare the two cases given their substantial environmental differences.

Soundings for the two events are provided in Fig. 7. The main difference between the two is the Bald Fire plume developed in quite dry conditions with a capping inversion above $700 \mathrm{hPa}$ (Fig. 7a), while the Sedgerly Rd sounding shows a classic inverted-V (Fig. 7b) with the boundary layer specific 
humidity about double that of the Bald Fire case. The drier conditions result in a more elevated $z_{\mathrm{fc}}$ for the Bald Fire of about $4.4 \mathrm{~km}$ compared with about $2.8 \mathrm{~km}$ for the Sedgerly $\mathrm{Rd}$ Fire. The drier conditions and capping inversion for the Bald Fire contribute to a relatively large $\Delta \theta_{\mathrm{fc}} \sim 8^{\circ} \mathrm{C}$, compared with the minimal $\Delta \theta_{\mathrm{fc}} \sim 1^{\circ} \mathrm{C}$ associated with the inverted-V profile of the Sedgerly Rd Fire. Corresponding PFT estimates using the manual analysis method yields about 140 and $12 \mathrm{GW}$, based on $U_{\mathrm{ML}}$ estimates of 3 and $5 \mathrm{~m} \mathrm{~s}^{-1}$, respectively.

The substantial difference in $\Delta \theta_{\mathrm{fc}}$ for the two cases also has implications for the relative buoyancies and plume slopes at the respective free-convection heights (assuming the firepower is similar to the diagnosed PFT). Since $b \propto \Delta \theta_{\mathrm{fc}}$ [Eq. (9)] the minimum free convection buoyancy for pyroCb formation would have been about 8 times greater for the Bald Fire than the Sedgerly Rd Fire. The differences in plume-centerline slope between the two fires can be estimated using Eq. (21), and using the PFT estimates in place of $B_{\text {flux }}$ in Eq. (18), and $z_{\mathrm{fc}} \sim z_{\text {con }}$. The slope ratio is

$$
\frac{\text { slope }_{B}}{\text { slope }_{S}}=\left[\frac{\mathrm{PFT}_{B}}{\mathrm{PFT}_{S}} \frac{z_{\text {con }, S}}{z_{\text {con }, B}}\left(\frac{U_{S}}{U_{B}}\right)^{3}\right]^{1 / 2} \sim 5.9,
$$

suggesting the Bald Fire would have been about 6 times steeper than the Sedgerly Rd Fire, which is consistent with the differences in slope of the two plumes shown in Fig. 7.

\section{Summary}

Athough the FireCAPE approach to pyroCb prediction has been used for some years, it is ad hoc and its implementation is highly subjective, with no recognized standard procedure for choosing an appropriate condensation level or the temperature and moisture increments that represent the plume thermodynamics at condensation. A further disadvantage is that it does not incorporate kinematic influences on plume behavior. In this paper, an alternative approach is introduced in which the pyroCb potential is represented as a minimum firepower required for pyroCb formation in a given environment: the pyroCb firepower threshold (PFT). The simplest PFT derivation that incorporated essential plume-rise dynamics was presented, yielding an analytic PFT solution comprising three main terms. Each term provides useful qualitative insight into fundamental properties of the atmosphere that impact pyroCb formation potential. The simplicity also ensures the diagnostic is transparent to users. It is anticipated that additional complexity will be built into future PFTs once real-time application and further experimentation reveal opportunities for refinement. This simple PFT procedure includes:

1) A specific process for determining the mixed-layer potential temperature and specific humidity $\left(\theta_{\mathrm{ML}}, q_{\mathrm{ML}}\right)$ and the associated mixed-layer lifting condensation level (ML-LCL), which represents thermodynamic properties of air entrained into a plume that rises sufficiently for condensation to occur.
2) A specific ratio of temperature to moisture increments added to $\theta_{\mathrm{ML}}$ and $q_{\mathrm{ML}}$ that represent the plume thermodynamics at condensation, consistent with Luderer et al. (2009) and Tory et al. (2018).

3) The use of this ratio and $\theta_{\mathrm{ML}}$ and $q_{\mathrm{ML}}$ to define a set of hypothetical plume saturation points (SP) on a thermodynamic diagram (the SP curve of Tory et al. 2018) and hence the origin of all hypothetical moist-plume pathways.

4) The selection of the coolest moist plume pathway that has sufficient buoyancy to rise freely from the SP curve to the minimum cloud-top height $\left(-20^{\circ} \mathrm{C}\right)$, to represent a minimumthreshold plume moist entropy at condensation for pyroCb to develop.

5) A procedure for determining the height the plume must rise, with this minimum moist entropy (the free convection height $\left.z_{\mathrm{fc}}\right)$, in order to follow the coolest moist pathway, and how much warmer than $\theta_{\mathrm{ML}}\left(\Delta \theta_{\mathrm{fc}}\right)$ it must be. These $\left(z_{\mathrm{fc}}\right.$ and $\left.\Delta \theta_{\text {fc }}\right)$ are two of three main properties that largely determine the favorability of the atmosphere for supporting pyroCb formation.

6) A method for determining a representative wind speed for $U_{\mathrm{ML}}$, the third main property that inhibits plume rise.

7) A procedure for combining these three factors $\left(z_{\mathrm{fc}}, \Delta \theta\right.$, and $U_{\mathrm{ML}}$ ) into a single measure of atmospheric pyroCb formation favorability, using Briggs's plume model.

This methodology allows users to calculate PFT from a single column of temperature, moisture and wind data. While it is not yet possible to verify the actual firepower values predicted by this PFT diagnostic, they can be used to establish an understanding of relative threat in different environments, and how variability in the input variables impacts the relative threat.

Additional insight into plume behavior and dynamics can be gained from the Briggs's equations alone. The plume centerline height [Eq. (1)] and slope [Eq. (17)] at a given downstream position is proportional to the cube root of the buoyancy length scale $l_{b}$, which is the ratio of the buoyancy flux $B_{\text {flux }}$ to the horizontal wind speed cubed $U^{3}$ [Eq. (18)]. Consequently, the plume height and slope are much more sensitive to changes in wind speed than changes in firepower, e.g., an eightfold increase in firepower is equivalent to halving the wind speed. Although, the impact of surface wind fluctuations on firepower would be expected to partly offset these changes to plume height and slope.

Focusing instead on the plume condensation height $z_{\text {con }}$ (rather than a specific downstream position), changes to $l_{b}$ have an even greater impact on the plume slope. An eightfold increase in $l_{b}$ almost triples $(\sqrt{8})$ the plume slope at $z_{\text {con }}$ [Eq. (21)] and brings it almost 3 times closer to the heat source [Eq. (20)], which may have implications for fire behavior when the atmospheric adjustment to the developing moist plume projects to the surface (e.g., enhanced indrafts).

The plume buoyancy $b$ at the condensation height is a function of the ratio of the buoyancy flux to the background wind speed (Eq. 22), which means variations in $b$ with changes in $l_{b}$ are dependent on how $l_{b}$ changes. In general, increasing $l_{b}$ will increase the buoyancy at $z_{\text {con }}$, leading to a general rule of thumb that the steeper the plume at cloud 
base, the greater the plume buoyancy there (and the greater the chance of pyroCb formation). However, exceptions occur when changes to $B_{\text {flux }}$ and $U$ are of the same sign, and the change to $B_{\text {flux }}$ is greater than the change to $U$ but less than the change to $U^{3}$. In these specific instances the plume buoyancy can increase while the plume slope decreases at $z_{\text {con }}$ and vice versa.

Finally, the PFT equation itself provides valuable insight into the relative importance of the three main ingredients that determine the favorability of the environment for pyroCb formation: free convection height $z_{\mathrm{fc}}$, free convection potential temperature increment $\Delta \theta_{\mathrm{fc}}$ [which is proportional to the free-convection buoyancy, Eq. (9)], and the mixed-layer wind speed $U_{\mathrm{ML}}$. These terms confirm the intuitive relationships between plume behavior, fire intensity, and atmospheric state. The taller the plume needs to be $\left(z_{\mathrm{fc}}\right)$ the greater the fire power required. The stronger the wind $\left(U_{\mathrm{ML}}\right)$ the greater the firepower required to counter the tendency for the plume to tilt over in the wind. The greater the capping inversion or stable layer that the plume must penetrate, the larger $\Delta \theta_{\mathrm{fc}}$ must be, and the greater fire power required. However, the real insight is in the combination of these terms, which enables the identification of an overall change in pyroCb formation threat when each of the three ingredients change.

Acknowledgments. Thanks to James Pescott and Will Thurston for their manuscript review, and to Kevin Parkyn, David Grant, Zach Berry-Porter, and David Wilke for discussions on pyroCb forecasting. Thanks also to Nick McCarthy for the images in Fig. 7b, and to Paul Simakoff-Ellims for use of the photo in Fig. 3. This work is supported through funding from the Earth Systems and Climate Change Hub of the Australian Government's National Environmental Science Programme (NESP).

Data availability statement. The radiosonde data plotted in Fig. $7 \mathrm{~b}$ are unpublished data. Radiosonde data plotted in Figs 1, 5, and 6 can be accessed from http://weather.uwyo.edu/ upperair/sounding.html.

\section{APPENDIX A}

\section{Derivation of the Briggs's Plume Centerline Height Equation}

The Briggs plume centerline height equation [Eq. (1)] is derived from the volume flux equation [Eq. (11)] and the vertical momentum flux equation [Eq. (13)]. Converting Eq. (11) to a vertical gradient using $d x / d z=U / w$,

$$
\frac{d\left(\pi R^{2} U\right)}{d z}=2 \pi R \beta U
$$

yields the trivial solution $R=\beta z_{c}$ [Eq. (2)] described in the introduction. Substituting Eq. (2) into Eq. (13), dropping the density term on both sides of the equation, and expressing as a time derivative using $(d / d t)=(d x / d t)(d / d x)=$ $U(d / d x)$ :

$$
\frac{d\left(\pi \beta^{2} z_{c}^{2} U w\right)}{d t}=B_{\text {flux }}
$$

Integrating with respect to time and using $w=d z_{c} / d t$ :

$$
z_{c}^{2} \frac{d z_{c}}{d t}=\frac{B_{\text {flux }} t}{\pi \beta^{2} U}
$$

From the chain rule, $d z_{c}^{3} / d t=3 z_{c}^{2}\left(d z_{c} / d t\right)$, hence,

$$
\frac{d z_{c}^{3}}{d t}=\frac{3 B_{\text {flux }} t}{\pi \beta^{2} U}
$$

Integrating with respect to time and taking the cube root of both sides:

$$
z_{c}=\left(\frac{3 B_{\mathrm{flux}} t^{2}}{2 \pi \beta^{2} U}\right)^{1 / 3}
$$

This is the plume centerline height equation expressed as a function of time. Use $x=U t$ to return to Eq. (1).

\section{APPENDIX B}

\section{Derivation of $\Delta H$ Used in the Heat Flux Equation}

In this derivation, it is assumed that dry static energy per unit mass $\left(S_{d}\right)$ is conserved in the plume (negligible energy losses to radiation) and that mixing of plume air and air from the surrounding environment results in an average $S_{d}$ matching the relative mass fractions of the two sources. By definition,

$$
S_{d}=C_{p d} T+g z,
$$

where $C_{p d}, T, g$, and $z$ are the specific heat of dry air, temperature, gravitational constant, and height, respectively. Expressing $S_{d}$ with respect to a reference-pressure height $z_{0}=z\left(P_{0}\right)$, then,

$$
S_{d}=C_{p d} T+g \Delta z=C_{p d} \theta,
$$

where $\Delta z=z-z_{0}$, and $\theta$ is the potential temperature relative to the reference pressure $P_{0}$.

Conservation of mass dictates that the mass flux on a vertical cross section through the plume ( $m_{\text {flux }}$, as depicted in Fig. 2$)$ is equal to the mass flux entering the plume at the source $\left(m_{\text {flux,in }}\right)$ plus the mass flux entrained between the source and cross section $\left(m_{\text {flux,ent }}\right)$ :

$$
m_{\text {flux }}=m_{\text {flux,in }}+m_{\text {flux,ent }} .
$$

Noting that the $S_{d}$ flux is the product of $S_{d}$ and the mass flux, the $S_{d}$ flux through a plume cross section $\left(S_{d, \mathrm{pl}} m_{\mathrm{flux}}\right)$ is equal to the $S_{d}$ flux entering the plume at the source $\left(S_{d, \text { in }} m_{\text {flux,in }}\right)$, plus the sensible heat flux $\left(H_{\text {flux }}\right)$, and the entrained $S_{d}$ flux $\left(S_{d, \text { ent }} m_{\text {flux,ent }}\right)$ : 


$$
S_{d, \mathrm{pl}} m_{\mathrm{flux}}=S_{d, \text { in }} m_{\text {flux,in }}+H_{\text {flux }}+S_{d, \text { ent }} m_{\text {flux,ent }} .
$$

In the neutral atmosphere the environment potential temperature is constant, which means

$$
S_{d, \text { in }}=S_{d, \text { ent }}=S_{d, \text { env }}=C_{p d} \theta_{\text {env }} .
$$

Here the subscript "env" refers to the neutral environment. From Eqs. (B3)-(B5),

$$
H_{\text {flux }}=\left(S_{d, \mathrm{pl}}-S_{d, \mathrm{env}}\right) m_{\mathrm{flux}}=\left(C_{p d} \Delta \theta\right) m_{\mathrm{flux}},
$$

where $\Delta \theta=\theta_{\mathrm{pl}}-\theta_{\mathrm{env}}$. It follows from Eqs. (5), (8), and (B6) that

$$
\Delta H=\rho_{0} C_{p d} \Delta \theta
$$

\section{APPENDIX C}

\section{Method Used to Express a Circle Area Fraction $(\alpha)$ as a Circle Radius Fraction $\left(\alpha^{\prime}\right)$}

The area of a circle cut by the intersection of a horizontal line, depicted in Fig. 2, can be expressed as a fraction $\alpha$ of the full circle:

$$
A=\alpha\left(\pi R^{\prime 2}\right)
$$

It can also be expressed in terms of the fraction of the circle radius ( $\alpha^{\prime}$ in Fig. 2$)$ between the circle origin and the horizontal line. Here, a method for determining $\alpha^{\prime}$ corresponding to a specified value of $\alpha$ is presented.

Let $\phi$ be the angle between the vertical and the radius intersecting the horizontal line at the circle edge (Fig. 2), then

$$
\alpha^{\prime}=\cos \phi
$$

and the circle segment area $\left(\mathrm{SA}_{\phi}\right)$ subtended by the angle $\phi$ is

$$
\mathrm{SA}_{\phi}=\frac{\phi}{2} R^{\prime 2}
$$

The triangular area within this part-circle segment $\left(\mathrm{TA}_{\phi}\right)$ is

$$
\mathrm{TA}_{\phi}=\frac{1}{2} R^{\prime} \cos \phi R^{\prime} \sin \phi=\frac{R^{\prime 2}}{4} \sin 2 \phi
$$

Thus, the difference between $\mathrm{SA}_{\phi}$ and $\mathrm{TA}_{\phi}$ is half $A$, therefore,

$$
A=\left(\phi-\frac{1}{2} \sin 2 \phi\right) R^{\prime 2} .
$$

From Eqs. (C1) and (C5),

$$
\alpha=\frac{\phi-\frac{1}{2} \sin 2 \phi}{\pi} .
$$

To find $\alpha^{\prime}$ using Eqs. (C2) and (C6) is solved for $\phi$ using Newton's method:

$$
\begin{aligned}
& f(\phi)=\phi-\frac{1}{2} \sin 2 \phi-\alpha \pi, \\
& f^{\prime}(\phi)=1-\cos 2 \phi, \\
& \phi_{n+1}=\phi_{n}-f\left(\phi_{n}\right) / f^{\prime}\left(\phi_{n}\right) .
\end{aligned}
$$

\section{APPENDIX D}

\section{Method for Estimating Firepower from Fire-Spread Rate Observations}

Using aerial observations and other fire intelligence, the rate of area burned is estimated and converted to a firepower using Eq. 10 of Harris et al. (2012) modified to account for energy lost to radiation:

$$
\mathrm{FP}=\alpha h w_{a} \frac{d A}{d t},
$$

where $\alpha=0.7$ is the fraction of sensible heat entering the plume (assuming a $30 \%$ loss to radiation), $h=15 \mathrm{MJ} \mathrm{kg}^{-1}$ is the heat yield of the fuel, $w_{a}$ is the fine fuel available for burning and ranges from about 1.25 to $4 \mathrm{~kg} \mathrm{~m}^{-2}$, and $d A / d t$ is the rate of area burned $\left(\mathrm{m}^{2} \mathrm{~s}^{-1}\right)$. These numbers vary with fuel type. For example, firepower estimates for the Chisholm Fire ASRD (2001, p. 67) quote estimates of surface fuel burned of up to $9.4 \mathrm{~kg} \mathrm{~m}^{-2}$, and use $h=18.7 \mathrm{MJ} \mathrm{kg}^{-1}$.

Note, firepower is often expressed as power per unit area $\left(\mathrm{W} \mathrm{m}^{-2}\right.$ ). The firepower (FP) in Eq. (D1) represents the total firepower for the entire area burned (W), averaged over the time period $d t$.

\section{REFERENCES}

ASRD, 2001: Final Documentation Report-Chisholm Fire (LWF-063). Forest Protection Division, Tech. Rep., Alberta Sustainable Resource Development, 53 pp.

Badlan, R. L., J. J. Sharples, J. P. Evans, and R. H. D. McRae, 2019: Insights into the role of fire geometry and violent pyroconvection. Proc. 23rd Int. Congress on Modelling and Simulation, Canberra, Australia, MSSANZ, 726-732, https:// mssanz.org.au/modsim2019/H7/badlan.pdf.

Baum, H. R., and B. J. McCaffrey, 1989: Fire induced flowfield-Theory and experiment. Fire Safety Science: Proceedings of the Second International Symposium, T. Wakamatsu, Ed., Hemisphere Publishing Newport, 129-148.

Briggs, G. A., 1975: Plume rise predictions. Lectures on Air Pollution and Environmental Impact Analyses, D. A. Haugen, Ed., Amer. Meteor. Soc., 59-111.

, 1984: Plume rise and buoyancy effects. Atmospheric Science and Power Production, D. Randerson, Ed., U.S. Dept. of Energy DOE/TIC-27601, 327-366.

Cruz, M. G., A. L. Sullivan, J. S. Gould, N. C. Sims, A. J. Bannister, J. J. Hollis, and R. J. Hurley, 2012: Anatomy of a catastrophic wildfire: The Black Saturday Kilmore East Fire in Victoria, Australia. For. Ecol. Manage., 284, 269-285, https://doi.org/ 10.1016/j.foreco.2012.02.035.

Dowdy, A. J., M. D. Fromm, and N. McCarthy, 2017: Pyrocumulonimbus lightning and fire ignition on Black Saturday in southeast Australia. J. Geophys. Res. Atmos., 122, 7342-7354, https://doi.org/10.1002/2017JD026577. 
Fromm, M. D., A. Tupper, D. Rosenfeld, R. Servranckx, and R. McRae, 2006: Violent pyro-convective storm devastates Australia's capital and pollutes the stratosphere. Geophys. Res. Lett., 33, L05815, https://doi.org/10.1029/2005GL025161.

_ R. H. D. McRae, J. J. Sharples, and G. P. Kablick III, 2012: Pyrocumulonimbus pair in Wollemi and Blue Mountains National Parks, 22 November 2006. Aust. Meteor. Ocean J., 62, 117-126, https://doi.org/10.22499/2.6203.001.

Harris, S., W. Anderson, M. Kilinc, and L. Fogarty, 2012: The relationship between fire behaviour measures and community loss: An exploratory analysis for developing a bushfire severity scale. Nat. Hazards, 63, 391-415, https://doi.org/ 10.1007/s11069-012-0156-y.

Kaye, N. B., and G. R. Hunt, 2009: An experimental study of large area source turbulent plumes. Int. J. Heat Fluid Flow, 30, 1099-1105, https://doi.org/10.1016/j.ijheatfluidflow.2009.05.001.

Lareau, N. P., and C. B. Clements, 2016: Environmental controls on pyrocumulus and pyrocumulonimbus initiation and development. Atmos. Chem. Phys., 16, 4005-4022, https://doi.org/ 10.5194/acp-16-4005-2016.

— , and — 2017: The mean and turbulent properties of a wildfire convective plume. J. Appl. Meteor. Climatol., 56, 2289-2299, https://doi.org/10.1175/JAMC-D-16-0384.1.

Luderer, G., J. Trentmann, and M. O. Andreae, 2009: A new look at the role of fire released moisture on the dynamics of atmospheric pyro-convection. Int. J. Wildland Fire, 18, 554-562, https://doi.org/10.1071/WF07035.

McRae, R. H. D., J. J. Sharples, S. R. Wilkes, and A. Walker, 2012: An Australian pyro-tornadogenesis event. Nat. Hazards, 65 , 1801-1811, https://doi.org/10.1007/s11069-012-0443-7.

__, __ and M. Fromm, 2015: Linking local wildfire dynamics to pyroCb development. Nat. Hazards Earth Syst. Sci., 15, 417-428, https://doi.org/10.5194/nhess-15-417-2015.
Peterson, D. A., E. J. Hyer, J. R. Campbell, J. E. Solbrig, and M. D. Fromm, 2017: A conceptual model for development of intense pyrocumulus in western North America. Mon. Wea. Rev., 145, 2235-2255, https://doi.org/10.1175/MWR-D-16-0232.1.

Potter, B. E., 2005: The role of released moisture in the atmospheric dynamics associated with wildland fires. Int. J. Wildland Fire, 14, 77-84, https://doi.org/10.1071/WF04045.

Rosenfeld, D., M. D. Fromm, J. Trentmann, G. Luderer, M. O. Andreae, and R. Servanckx, 2007: The Chisolm Firestorm: Observed microstructure, precipitation and lightning activity of a pyro-cumulonimbus. Atmos. Chem. Phys., 7, 645-659, https://doi.org/10.5194/acp-7-645-2007.

Stull, R. B., 1988: An Introduction to Boundary Layer Meteorology. Kluwer Academic Publishers, 666 pp.

Tory, K. J., 2018: Models of buoyant plume rise. Bushfire and Natural Hazards Cooperative Research Centre Research Rep. 451, 26 pp., https://www.bnhcrc.com.au/publications/ biblio/bnh-5267.

— W W. Thurston, and J. D. Kepert, 2018: Thermodynamics of pyrocumulus: A conceptual study. Mon. Wea. Rev., 146, 2579-2598, https://doi.org/10.1175/MWR-D-17-0377.1.

Trelles, J., K. B. McGrattan, and H. R. Baum, 1999: Smoke dispersion from multiple fire plumes. AIAA J., 37, 1588-1601, https://doi.org/10.2514/2.659.

Trentmann, J., G. Luderer, T. Winterrath, M. D. Fromm, R. Servranckx, M. Herzog, H.-F. Graf, and M. O. Andreae, 2006: Modeling of biomass smoke injection into the lower stratosphere by a large forest fire (Part I): Reference simulation. Atmos. Chem. Phys., 6, 5247-5260, https://doi.org/ 10.5194/acp-6-5247-2006.

Weil, J. C., 1988: Plume rise. Lectures on Air Pollution Modeling, A. Venkatram, and J. C. Wyngaard, Eds., Amer. Meteor. Soc., 119-166, https://doi.org/10.1007/978-1-935704-16-4_4. 